\title{
Adaptation of the gut holobiont to malnutrition during mouse pregnancy depends on the type of nutritional adversity
}

\author{
Kristin L Connor ${ }^{1,2}$, Enrrico Bloise ${ }^{3}$, Todd Z DeSantis ${ }^{4}$, Stephen J Lye $\mathbf{~}^{2,5}$. \\ 1. Department of Health Sciences, Carleton University \\ 2. Lunenfeld-Tanenbaum Research Institute, Mount Sinai Hospital, Toronto, Ontario, Canada. \\ 3. Department of Morphology, Federal University of Minas Gerais , Belo Horizonte, Brazil \\ 4. Second Genome, San Francisco, California, United States of America \\ 5. Department of Obstetrics and Gynaecology, University of Toronto, Toronto, Ontario, Canada \\ *Correspondence: Dr. Kristin Connor, Department of Health Sciences, Carleton University, 1125 Colonel By Drive, 3310 Health \\ Sciences Building, Ottawa, ON, Canada, kristin.connor@carleton.ca
}

\begin{abstract}
Malnutrition can influence maternal physiology and programme offspring development. Yet, in pregnancy, little is known about how dietary challenges that influence maternal phenotype affect gut structure and function. Emerging evidence suggests that interactions between the environment, multidrug resistance (MDR) transporters and microbes may influence maternal adaptation to pregnancy and regulate fetoplacental development. We hypothesised that the pregnancy gut holobiont (host and microbes) adapts differently to suboptimal maternal diets, evidenced by changes in the gut microenvironment, morphology, and expression of key protective MDR transporters during pregnancy. Mice were fed a control diet (CON) during pregnancy, or undernourished (UN) by $30 \%$ of control intake from gestational day (GD)5.5-18.5, or fed $60 \%$ high fat diet (HF) for eight weeks before and during pregnancy. At GD18.5, maternal small intestinal (SI) architecture (H\&E), proliferation (Ki67), P-glycoprotein (P-gp - encoded by $A b c b 1 a / b)$ and breast cancer resistance protein (BCRP/Abcg2) MDR transporter expression and levels of pro-inflammatory biomarkers were assessed. Circulating inflammatory biomarkers and maternal caecal microbiome composition (G3 PhyloChipTM) were measured. MDR transporter expression was also assessed in fetal gut. HF diet increased maternal SI crypt depth and proinflammatory load, and decreased SI expression of $A b c b 1 a$ mRNA, whilst UN increased SI villi proliferation and $A b c b 1 a$, but decreased $A b c g 2$, mRNA expression. There were significant associations between $A b c b 1 a$ and $A b c g 2$ mRNA levels with relative abundance of specific microbial taxa. Using a systems physiology approach we report that common nutritional adversities provoke adaptations in the pregnancy holobiont in mice, and reveal new mechanisms that could influence reproductive outcomes and fetal development.
\end{abstract}

Keywords: pregnancy, gut, nutrition, multidrug resistance, inflammation

\section{Introduction}

Undernutrition and overnutrition before and during pregnancy adversely impact reproductive outcomes. Both forms of malnutrition are associated with maladaptations to pregnancy, including altered endocrine function[1-3], increased maternal susceptibility to infections and lowgrade inflammation[4-6], as well as poor development of the placenta and offspring antenatally and postnatally[7, 8]. Rates of maternal undernutrition and underweight are increasing[8], and progressively, more populations are facing overnutrition and epidemics of obesity[9, 10], including those undergoing transitions in nutrition[11].

In the non-pregnant state, malnutrition can have profound effects on gut structure and function. This includes altered intestinal architecture and histomorphological changes in key cell types[12], and functional changes including reduced barrier integrity/defence and an altered gut microbiome[13-15]. These changes are associated with compromised health outcomes such as poor growth and metabolic/immune dysfunction. The intestinal epithelium directly senses and responds to the external environment $[16,17]$, and these adaptations can determine allostasis and homeostasis locally at the gut and systemically beyond the gut, collectively to protect the host and influence health.
Multidrug resistance (MDR) transporters, such as P-glycoprotein (P-gp encoded by $A b c b l a / b$ genes) and breast cancer resistance protein (BCRP/Abcg2), belong to the ATP-binding cassette (ABC) family of transporters, and establish an additional key defensive barrier between the gut and the intestinal lumen that contributes to intestinal homeostasis[18]. MDRs are mostly distributed on the apical surface of intestinal epithelial cells[19-21] and support the physical, selective barrier of the intestinal epithelium through their ability to efflux an array of substances across biological membranes, preventing the gut from absorbing potentially harmful substances into the body. Intestinal P-gp and BCRP regulate gut absorption, biodistribution, and metabolism of an array of obstetric-relevant substrates including: 1. nutrients (folate, haem/iron, flavonoids), 2. cytokines and chemokines (chemokine [C-C motif] ligand 2 [CCL2], granulocyte-macrophage colony-stimulating factor [GM-CSF], interleukin[IL]-1 $\beta$, IL-2, IL-4, IL-6, interferon[IFN]$\gamma$, tumor necrosis factor [TNF]- $\alpha$ ), 3 . toxicants (carcinogens phototoxic compounds, estrogenic mycotoxins, select mercuric species, ivermectin) and 4. drugs (anti-retrovirals, antibiotics, synthetic glucocorticoids, sulfonylureas, nonsteroidal anti-inflammatory drugs, proton pump inhibitors)[22, 23]. Malnutrition[24] and metabolic disease[25, 26] in the non-pregnant state alter MDR expression and function. Yet, little is known about how dietary challenges that influence pregnancy phenotype 
affect gut structure and function, including gut MDR transporters, in pregnancy.

Importantly the host is not, and probably has never been, an "autonomous entity"[27]. More accurately, there is clear cooperation and dependence between the host and the community of microbes living in and on it. This holobiont ("the unit of biological organisation composed of a host and its microbes"[27]) senses and responds to the environment, and influences host physiology (including states of health and disease)[28, 29] and behaviour[30], affecting an individual's phenotype. Emerging evidence suggests that one important interaction within the holobiont occurs between gut microbes and intestinal epithelial MDR transporters, where variation in this relationship can lead to an oscillation between health and diseased states[18]. In reproduction, the holobiont is especially important, since this real-time sensor of the pregnancy environment could instruct maternal adaptations to pregnancy, and even regulate fetoplacental development and function[31, 32], possibly through interactions with MDRs.

Although we know how some nutritional exposures affect selected features of the gut[33], including in pregnancy[34, 35], little is known about the interactions between gut microbes and MDR transporters, and what, if any, functional consequence there might be for the host if these relationships are altered. Not all pregnancies exposed to malnutrition show compromised maternal physiology or health, which could be explained by the extent to which the gut holobiont can adapt to changes in the pregnancy environment, and thus act as a selective barrier for trophic factors and xenobiotics[36]. If we can identify the situations where the holobiont maladapts to environmental exposures, and understand the mechanisms that underlie these maladaptations, we are better positioned to pinpoint the most at-risk pregnancies or especially detrimental early environments, and target these mechanistic pathways to correct holobiont function and prevent poor reproductive health and outcomes.

To address this gap, we evaluated the effects of malnutrition during pregnancy on the gut holobiont in a mouse model. We hypothesised that the pregnancy gut holobiont adapts differently to suboptimal maternal diets, evidenced by changes in the gut microenvironment, gut morphology, and the expression of key MDR transporters that protect the mother and developing fetus. We also hypothesised that these dietary challenges would programme the same transport pathways in the developing fetal gut. In taking a systems physiology approach, our study reveals a role for malnutrition in influencing the holobiont during pregnancy, with implications for pregnancy health and fetal development.

\section{Methods}

\section{Animal model}

The Animal Care Committee at Mount Sinai Hospital approved all experiments. Our animal model has been described in detail previously, and was established to model pregnancy phenotypes seen with undernutrition/underweight (reduced maternal weight gain with fetal growth restriction, without embryonic lethality or preterm birth) and overweight/obesity (maternal metabolic dysfunction, without fetal growth restriction) $[3,34,35]$. In brief, male and female C57BL/6 mice were obtained from Jackson Laboratories and housed in a single room under constant temperature $\left(25^{\circ} \mathrm{C}\right.$ and $12: 12$ light-dark cycle) with free access to food and water. Females were randomly divided into three nutritional groups: i) mice fed a control diet (Dustless Precision Pellets S0173, BioServe, Frenchtown, NJ, USA) ad libitum before mating and throughout pregnancy $(\mathrm{CON}, \mathrm{n}=7)$; or ii) mice fed a control diet $a d$ libitum before mating and until gestational day (GD) 5.5, and then undernourished (UN) by $30 \%$ of control intakes from GD5.5-17.5, after which females were fed control ad libitum for the remainder of the study $(n=7)$; iii) or mice fed a high fat diet $(60 \% \mathrm{kcal}$ as fat, D12492, Research Diets, New Brunswick, NJ, USA) ad libitum from 8 weeks before mating and throughout pregnancy $(\mathrm{HF}, \mathrm{n}=8)$. All breeding males were fed control diet ad libitum for the duration of the study. Females in estrus were housed with a male overnight at approximately 10 weeks of age, and mating was confirmed by the presence of a vaginal sperm plug the following morning, at which time (GD0.5) pregnant females were housed individually in cages with free access to water and their respective diets.

\section{Biospecimen collection and processing}

At the end of pregnancy (GD18.5, term = 19 days), dams were killed by cervical dislocation. Immediately following, dams were decapitated and trunk blood was collected into heparin-coated tubes for plasma isolation. Fetuses and placentae were rapidly dissected from the uterus, and tissues were flash frozen in liquid nitrogen and stored at $-80 \mathrm{C}$, or fixed in $10 \%$ neutral-buffered formalin. One male and one female fetus from each litter was used for later analyses. Maternal small intestine (SI) was isolated from the gastrointestinal tract as previously described[34, 35]. SI tissue was flash frozen in liquid nitrogen and stored at $-80 \mathrm{C}$, or fixed in $10 \%$ neutral-buffered formalin. Small intestinal intraepithelial lymphocytes were isolated from SI tissue for measurement of cytokines and chemokines, and DNA was extracted from caecal contents for 16S rRNA profiling, as previously described[35, 37].

\section{Histological analyses}

Five-micrometre paraffin-embedded maternal SI sections were stained with haematoxylin and eosin (H\&E) according to standard protocols to assess intestinal architecture and histological components, or specific primary and secondary antibodies as described below. To determine if suboptimal maternal nutrition confers architectural changes in the SI that have been documented in cases of starvation[12, 14] and diet-induced inflammation[15, 38, 39] in the non-pregnant state, villus height and crypt depth were assessed as described by Beuling et al.[40]. In brief, eight images were randomly captured at $20 \mathrm{X}$ magnification along the length of an H\&E stained SI section from each dam (Leica DMIL LED inverted microscope, Wetzlar, Germany; and QCapture Pro software, Surrey, BC, Canada). The length of one villi and its corresponding crypt were measured in each image (Image J version 1.51) first by determining the villi-crypt junction and then by measuring the length of the villi and crypt from that junction. A single investigator, blinded to the experimental groups, captured the images and performed the measurements.

Sections from each SI were also stained for Ki67, to determine the relative index of proliferation[41], and P-gp and BCRP, to assess expression and localisation of these multidrug resistance transporters. For Ki67 staining, sections were first rehydrated and then quenched using $0.3 \%$ hydrogen peroxide (Fisher, Toronto, ON, Canada) in methanol for $30 \mathrm{~min}$ at room temperature (RT). Sections underwent antigen retrieval first by boiling in 1X unmasking solution (DAKO, Mississauga, ON, Canada) for $30 \mathrm{~min}$ and next by boiling in $10 \mathrm{mM}$ sodium citrate solution for $8 \mathrm{~min}$. Sections were blocked using serum-free protein blocking solution (DAKO) for $1 \mathrm{~h}$ at RT and incubated overnight at $4^{\circ} \mathrm{C}$ with 1:100 dilution of mouse anti-Ki67 antibody (Novocastra, Concord, ON, Canada) in antibody diluent (DAKO). Next, a 1:200 dilution of goat biotinylated anti-mouse antibody (Vector Labs, Burlington, ON, Canada) in antibody diluent (DAKO) was applied for $1 \mathrm{~h}$ at RT, followed by a 1:2000 dilution of streptavidin-horseradish peroxidase (Invitrogen, Burlington, Canada) in $1 \times$ PBS for $1 \mathrm{~h}$ at RT. DAB peroxidase substrate 
Maternal gut holobiont and malnutrition in pregnancy

(Vector Labs, Burlingame, CA, USA) was applied for $1 \mathrm{~min} 15 \mathrm{sec}$ to visualise the antibody signals. Between all steps, sections were washed three times with PBS with $0.1 \%$ Tween 20 . Sections were counterstained with Gill's \#1 haematoxylin. Monoclonal mouse IgG1 antibody (DAKO) served as the negative control. Four of eight images randomly captured SI images at $40 \mathrm{X}$ magnification (Leica DMIL LED inverted microscope and QCapture Pro software) were used for measuring relative index of proliferation. First, two villi and their crypts in each of the four images (eight villi and eight crypts in total per dam) were identified for quantification. In each villi and crypt, immunoreactive (ir)-Ki67 positive cells and unstained (negative) cells were counted, and these were summed within a villi and a crypt to obtain the total number of cells in the villus and in the crypt. The relative index of proliferation for each villus and crypt was calculated as the percentage of ir-Ki67 positive cells to total cells. The mean relative index of proliferation across the four villi and crypts for each dam was calculated. Image analysis was conducted by a single observer blinded to the experimental groups.

Staining for P-gp (1:500, D-11 Santa Cruz, Mississauga, Canada) and BCRP (1:200, Calbiochem, Etobicoke, ON, Canada) was conducted as described above with the following changes: sections were quenched using $0.03 \%$ hydrogen peroxide in $1 \mathrm{X}$ PBS for $30 \mathrm{~min}$ at RT; secondary antibody was goat biotinylated anti-mouse antibody (1:200, Vector Labs); and DAB peroxidase substrate incubation time to visualise antibody signals was $30 \mathrm{sec}$ for both P-gp and BCRP. From stained sections, eight images containing villi and crypts were randomly captured at 20X magnification (Leica DMIL LED inverted microscope and QCapture Pro software). Semiquantitative analysis to score staining intensity in each image was conducted by a single observer blinded to the experimental groups as described previously [34, 42]. Staining intensity was assessed in one villi and its adjacent crypt in each of the eight images in the following four regions: the apical membrane of the villus, the remainder of the same villus (not including apical membrane), the apical membrane of the crypt, and the remainder of the crypt (not including the apical membrane). Staining was scored as absent (0), weak (1), moderate (2), strong (3) and very strong (4). Mean staining intensity across the eight images for each region of the SI was calculated.

\section{Cytokine analysis from maternal plasma and SI IEL protein}

Maternal plasma and SI IEL proteins were assayed for cytokine levels according to manufacturer's instructions using the Bio-Plex Pro Mouse Cytokine 23-Plex Assay (Bio-Rad, Mississauga, Canada) and the Luminex system (Bio-Rad; software v6.0). SI IEL samples from 19 dams were assayed and plasma samples from 14-19 dams were assayed. Cytokine concentrations are expressed as $\mathrm{pg} / \mathrm{mL}$ for plasma and $\mathrm{pg} / \mathrm{mg}$ protein for SI IEL total protein. Cytokines with values above or below the standard curve range were excluded from analyses leaving 19 and 15 cytokines for maternal plasma and SI IEL analyses, respectively.

\section{RNA isolation and mRNA expression in maternal and fetal tissues}

Total RNA was extracted from maternal SI and cerebellum following manufacturer's protocol (QIAGEN RNeasy Plus Mini Kit, Toronto, Canada) and the Tissue Lyser II (Qiagen, Toronto, Canada) at $30 \mathrm{~Hz}$ for 3 minutes. RNA was extracted from fetal gut following manufacturer's protocol (QIAGEN RNeasy Micro kit, Toronto, Canada) and the Tissue Lyser II at $20 \mathrm{~Hz}$ for 2 minutes, twice. RNA quality and quantity were assessed using the Experion StdSens Analysis Kit and LapChip (BioRad, Mississauga, Canada) according to manufacturer's protocol and by nanodrop. $1 \mu \mathrm{g}$ RNA was reverse transcribed using 5X iScript Reverse Transcription Supermix (Bio-Rad, Mississauga, Canada).
Real-time qPCR (Bio-Rad CFX384, Hercules, CA, USA) was used to measure expression of $A b c b 1 a$ and $A b c b 1 b$ (encoding P-gp) and $A b c g 2$ (encoding BCRP) in maternal SI and fetal gut. Expression levels in maternal cerebella were measured as a control to evaluate whether malnutrition targeted MDR expression in a tissue-dependent manner. Primer sequences for genes of interest and three stably expressed reference genes (maternal SI: $A c t b$ [encoding $\beta$-actin], Tbp [encoding TATA-box binding protein], Ywhaz [encoding 14-3-3 protein zeta/delta]; cerebellum: Ppia [peptidylprolyl isomerase A], Tbp, Ywhaz; fetal gut: Actb, Tbp, Ywhaz) are in Table A.1. A non-template control (NTC; absence of cDNA template) was prepared as a negative control for the PCR reaction. Each real-time PCR reaction mix was prepared with SYBR Green JumpStart Taq ReadyMix (Sigma, Oakville, Canada) and forward and reverse primer mix $(3 \mu \mathrm{M})$ for each gene. Standard curves for each gene were run. Standards, samples and controls were run in triplicate under the following cycling conditions: $95^{\circ} \mathrm{C}$ for $20 \mathrm{~s} ; 40$ cycles of $95^{\circ} \mathrm{C}$ for $5 \mathrm{~s}$ and $60^{\circ} \mathrm{C}$ for $20 \mathrm{~s}$ and a melt curve at $65^{\circ} \mathrm{C} \rightarrow 95^{\circ} \mathrm{C}$ with a $0.5^{\circ} \mathrm{C}$ increment every $5 \mathrm{~s}$. Relative gene expression for each sample was calculated using the $\mathrm{Cq}$ value of the gene of interest relative to the geometric mean of the reference genes $\mathrm{Cq}$ values[43].

\section{Caecal DNA extraction, $16 S$ rRNA profiling and analysis}

In a subset of pregnancies from this cohort ( $n=5 /$ group), DNA was extracted from frozen caecal contents by bead beating and full-length $16 \mathrm{~S}$ rRNA gene sequences were amplified from variable regions 1 through 9 from each sample, and hybridised to the PhyloChip ${ }^{\mathrm{TM}}$ Array (version G3) as we previously described[35]. Empirical operational taxonomic units (eOTUs) were determined from the dataset and abundance tables for each eOTU were calculated as previously described[35, 44, 45].

\section{Statistics}

Outcome measures were tested for normality and unequal variances (Levene test). Data that were non-normal were transformed to achieve normality, where possible. Differences between dietary groups for outcome measures were determined by ANOVA with Tukey's post hoc, or Welch ANOVA with Games-Howell post hoc, or Kruskal-Wallis test with Steel-Dwass for nonparametric data $(p<0.05)$. Data are presented as means \pm standard deviation (SD) or median and interquartile range (IQR), with $95 \%$ confidence diamonds in figures. Data transformed for analyses are presented as untransformed values. Relationships between gene expression levels and relative index of proliferation in SI were determined by Spearman's correlation with data presented as means $\pm \mathrm{SD}$ with Spearman's rho $(\mathrm{p}<0.05)$, and $95 \%$ density ellipses in figures.

\section{Analysis of relationships between the microbiome and multidrug} resistance transporters

Significant differences between MDR gene expression levels and the microbiome were determined using the Adonis test. Spearman rank correlations test was used to determine relationships between each eOTU's abundance value and $A b c b 1 a$ and $A b c g 2$ mRNA expression levels. We corrected for multiple comparisons using the false discovery rate Benjamini Hochberg method and deemed corrected p-values (qvalues) that were less than 0.05 to be significant. Heatmaps were generated to visualise associations between relative bacterial abundance and continuous variables. A hierarchical clustering technique was used to summarise these relationships in the form of a dendogram. Biologically similar communities have a shorter branch length between them. 
Maternal gut holobiont and malnutrition in pregnancy

Assessment of features that contribute to gut homeostasis and discriminate mothers

We evaluated the cohort using principal components analysis (PCA) based on correlations to determine if we could discriminate mothers based on features related to variation in gut homeostasis: microbial abundance dissimilarity (using mean wUniFrac distance); SI IEL inflammatory load (using a summary score of SI IEL inflammatory biomarkers); relative index of proliferation (Ki67) in SI villi, and MDR mRNA expression (for both $A b c b l a$ and $A b c g 2$ genes). The SI IEL inflammation summary score was calculated by ranking each of the $7 \mathrm{SI}$ IEL inflammatory biomarkers that were significantly different between dietary groups from lowest to highest concentration for all 18 mothers in the cohort for which there were inflammatory measures. Rank values ranged from 1 to 18 , where higher values indicate greater inflammatory load. For each mother, a single summary score was calculated by summing the ranked value across each of the 7 biomarkers to derive a single summary score of SI IEL inflammatory load. Loadings of all features (variables) of each principal component (PC) were determined, and loadings most influential for each PC (i.e. the features that contributed the most to the $\mathrm{PC}$ ) were identified and are displayed in a table of loadings (Figure A.1).

\section{Results}

Maternal malnutrition alters intestinal architecture and cellular proliferation

Examination of maternal SI gross morphology revealed typical intestine histological components, i.e. the mucosa being formed by regular villi, lamina propria, crypt and goblet cells, and the submucosa formed by its typical inner and outer muscularis layers. In contrast, SI architecture was disrupted by maternal malnutrition. Maternal SI crypt depth was longer in HF mothers compared to CON and $\mathrm{UN}$ ( $\mathrm{p}=0.0002$, Figure 1 ), a $10.6 \%$ increase in depth vs. CON alone in HF (post hoc $\mathrm{p}=0.02$ ). Crypt depth was shorter $(8.6 \%$ decrease) in UN mothers compared to CON, but differences were not statistically significant. Villus height and villus:crypt length ratio were not altered by diet (Figure 1). Cellular proliferation in maternal SI crypts and villi were assessed by Ki67 staining (Figure 2A). The mean relative index of proliferation was significantly greater in $\mathrm{UN}$ villi $(83 \% \pm 7)$ vs. $\mathrm{HF}(52 \% \pm 13)$ and $\mathrm{CON}$ $(43 \% \pm 15)(p<0.0001$, Figure $2 B)$. There were no differences in proliferation index in the crypts across dietary groups $(75-79 \%$, Figure 2B).

Maternal HF diet elicits an inflammatory response locally in the SI To determine whether our models of UN and HF diets were associated with local or systemic inflammation, we measured a panel of proinflammatory cytokines and chemokines in maternal SI IEL and plasma. Levels of the pro-inflammatory cytokines and chemokines IL-1 $\alpha$, IL-1 $\beta$, GM-CSF, IFN $\gamma$, eotaxin and MCP-1 were markedly increased in SI IEL of HF compared to CON and UN mothers ( $p<0.05$; Table 1). IL-2 levels were also increased in HF compared to UN mothers $(p<0.05$, Table 1$)$, and there was an overall difference in levels of the pro-inflammatory cytokines IL-12 (p40) and IL-12 (p70) and the anti-inflammatory cytokine IL-10 between dietary groups $(\mathrm{p}<0.05)$, but no between group differences on post hoc analyses (Table 1). A visual synthesis of the significantly different inflammatory biomarker levels in maternal SI IEL clearly showed HF fed mothers had greater inflammatory load compared to CON and UN (Figure 3). Systemic inflammatory load was only modestly altered in a diet-dependent manner. Plasma levels of IL-12 (p40) were reduced in UN mothers and increased in HF mothers $(\mathrm{p}<0.0001)$ compared to CON (Table 2). Plasma levels of the chemokine RANTES, a pro-inflammatory mediator, were also increased in HF mothers compared to $\mathrm{CON}$ ( $\mathrm{p}<0.02$, Table 2$)$.
A
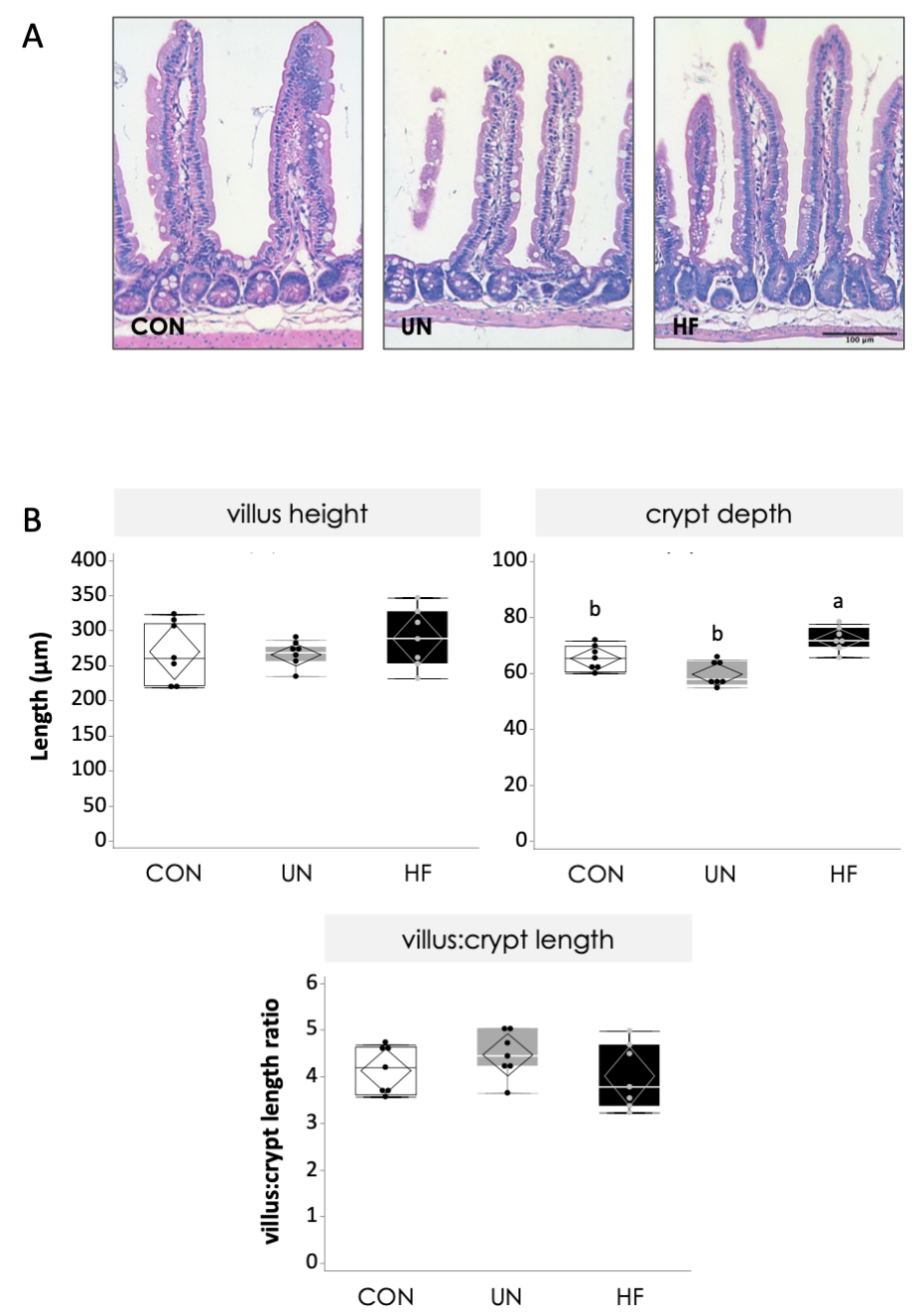

Figure 1. Maternal malnutrition affects small intestinal (SI) architecture and cellular proliferation at GD18.5. A. Representative images of H\&E stained maternal SI at 20X magnification. Scale bar $=100 \mu \mathrm{m}$. B. Length of villi and crypts (upper panel) and villus:crypt length ratio (lower panel). Data are quantile box plots with $95 \%$ CI confidence diamonds.

\section{Maternal malnutrition alters gut expression of multidrug resistance} transporters

To determine whether maternal malnutrition can alter P-gp and BCRP transport potential in the gut, we measured the expression levels and determined the maternal SI localisation of the multidrug resistance transporters $\mathrm{P}-\mathrm{gp} / A b c b 1 a / b$ and $\mathrm{BCRP} / A b c g 2$. UN was associated with a 3.7-fold increase in Abcbla mRNA expression in maternal SI compared to $\mathrm{CON}$ and $\mathrm{HF}$ ( $\mathrm{p}=0.0002$, Figure $4 \mathrm{~A}$ ) and a decrease in Abcg 2 mRNA expression in maternal SI compared to $\mathrm{CON}$ and $\mathrm{HF}(\mathrm{p}=0.004$, Figure 4C). There was no effect of maternal UN on $A b c b 1 b$ mRNA expression in maternal SI (Figure 4B). In the fetal gut, we did not observe any differences in $A b c b l a / b$ or $A b c g 2$ expression levels due to maternal UN or HF diets when analysing all fetuses, inclusive of sex (Figure 4), or when stratifying by fetal sex (Table A.2). Additionally, to determine whether the effects of maternal diet were tissue specific, we evaluated mRNA expression of our genes of interest in the maternal cerebella. HF dams showed reduced cerebellar $A b c b 1 b$ mRNA expression compared to $\mathrm{CON}(\mathrm{p}=0.04$. Figure $4 \mathrm{~B})$ and there was an overall slight difference in 
A

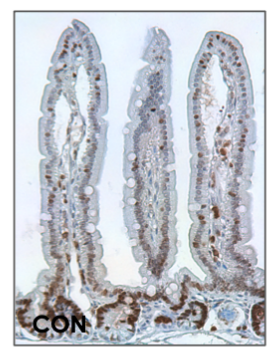

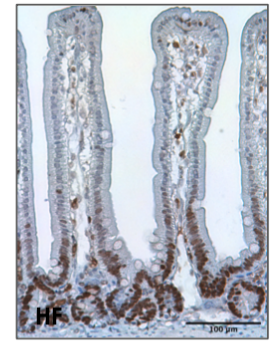

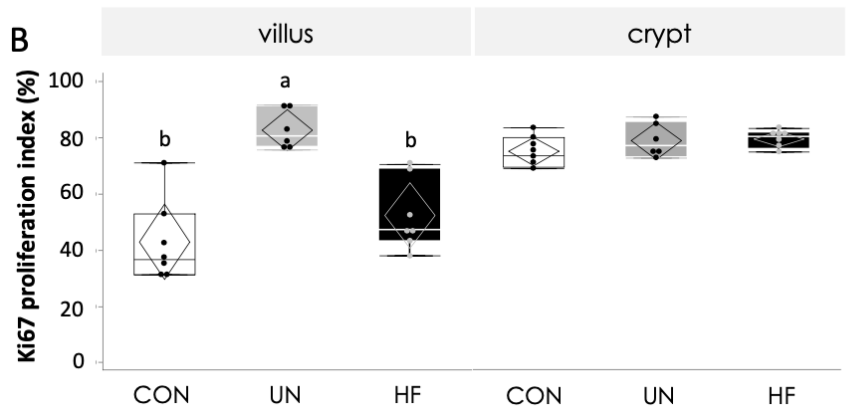

Figure 2. Maternal undernutrition affects cellular proliferation in the small intestine at GD18.5. A. Representative images of immunoreactive Ki67 staining maternal SI at 20X magnification with negative control (inset). Scale bar $=100$ $\mu \mathrm{m}$. B. Proliferation index in villi and crypts. Data are quantile box plots with $95 \%$ CI confidence diamonds.

Table 1. Inflammatory biomarkers in maternal small intestinal intraepithelial lymphocytes at GD18.5.

\begin{tabular}{|c|c|c|c|c|}
\hline $\begin{array}{c}\text { Biomarker } \\
\text { (pg/mg protein) }\end{array}$ & CON & UN & HF & p-value \\
\hline IL-1 $\boldsymbol{\alpha}$ & $2.8(1.9-5.2)^{\mathrm{b}}$ & $2.5(2.2-4.7)^{\mathrm{b}}$ & $10.0(5.6-16)^{\mathrm{a}}$ & 0.009 \\
\hline IL-1 $\boldsymbol{\beta}$ & $156 \pm 103^{\mathrm{b}}$ & $144 \pm 44^{\mathrm{b}}$ & $288 \pm 93^{\mathrm{a}}$ & 0.02 \\
\hline IL-2 & $6.6(5.3-14)^{\mathrm{ab}}$ & $6.4(4.9-12)^{\mathrm{b}}$ & $16.6(11-19)^{\mathrm{a}}$ & 0.03 \\
\hline IL-6 & $3.8(1.9-7.3)$ & $7.3(3.3-11)$ & $3.5(1.9-10)$ & NS \\
\hline IL-10 & $4.3 \pm 2.4$ & $4.1 \pm 1.9$ & $7.4 \pm 2.7$ & 0.049 \\
\hline IL-12 (p40) & $1.8(1.4-2.7)$ & $2.0(1.7-2.2)$ & $3.0(2.6-4.5)$ & 0.044 \\
\hline IL-12 (p70) & $82.6 \pm 64$ & $72.5 \pm 37$ & $141 \pm 37$ & 0.046 \\
\hline Eotaxin & $459 \pm 197^{\mathrm{b}}$ & $447 \pm 109^{\mathrm{b}}$ & $741 \pm 211^{\mathrm{a}}$ & 0.02 \\
\hline GM-CSF & $66.7 \pm 32^{\mathrm{b}}$ & $65.9 \pm 13^{\mathrm{b}}$ & $130 \pm 37^{\mathrm{a}}$ & 0.002 \\
\hline IFN- $\boldsymbol{\gamma}$ & $4.0(3.3-5.9)^{\mathrm{b}}$ & $4.2(3.5-5.1)^{\mathrm{b}}$ & $8.3(7.6-14)^{\mathrm{a}}$ & 0.0006 \\
\hline MCP-1 & $6.4(4.9-9.9)^{\mathrm{b}}$ & $6.4(5.7-10)^{\mathrm{b}}$ & $12.2(10-17)^{\mathrm{a}}$ & 0.01 \\
\hline MIP-1 $\boldsymbol{\alpha}$ & $14.5 \pm 9.9$ & $13.3 \pm 4.5$ & $20.3 \pm 6.5$ & NS \\
\hline MIP-1 $\boldsymbol{\beta}$ & $3.5 \pm 2.1$ & $4.1 \pm 0.72$ & $4.4 \pm 1.9$ & $\mathrm{NS}$ \\
\hline RANTES & $7.2(5.6-11)$ & $6.7(4.4-7.7)$ & $6.4(3.4-13)$ & NS \\
\hline TNF- $\boldsymbol{\alpha}$ & $49.0(27-189)$ & $126(65-193)$ & $67.0(42-192)$ & NS \\
\hline
\end{tabular}

Data are mean $\pm \mathrm{SD}$ or median (IQR). Groups with different letters are significantly different (Tukey's post hoc).

Abcg 2 mRNA expression in cerebella $(\mathrm{p}=0.046)$, but there were no significant differences between dietary groups on post hoc testing (Figure 4C). To establish whether alterations in maternal diet were related to changes in the distribution of P-gp and BCRP protein within the maternal intestinal mucosa (crypt and villi) and within the epithelial cell (membranous versus cytoplasmic), immunohistochemical analysis was performed. Immunoreactive (ir)-P-gp signal was detected in the villi and crypt epithelia in all mothers, with strongest staining localised to the apical membrane of the intestinal villi and weaker staining in the cytoplasm (Figure 5A-C). Visual assessment of ir-P-gp staining in villi and crypt revealed overall stronger P-gp immunostaining in the SI of UN mothers. ir-BCRP signal was present in villi and crypt surface epithelium and cytoplasm (Figure 5D-F), and staining was weakest in the SI of UN mothers. The cellular localisation of P-gp and BCRP proteins along the villi and crypts was similar in all mothers, irrespective of diet.

Table 2. Inflammatory biomarkers in maternal plasma at GD18.5.

\begin{tabular}{|c|c|c|c|c|}
\hline $\begin{array}{c}\text { Biomarker } \\
\text { (pg/mL) }\end{array}$ & CON & UN & HF & p-value \\
\hline IL-1 $\boldsymbol{\alpha}$ & $37.0 \pm 21$ & $40.5 \pm 28$ & $37.7 \pm 20$ & NS \\
\hline IL-1 $\beta$ & $199(73-344)$ & $251(75-364)$ & $330(206-426)$ & NS \\
\hline IL-2 & $55.5 \pm 32$ & $64.8 \pm 33$ & $61.8 \pm 17$ & NS \\
\hline IL-5 & $20.5 \pm 5.7$ & $17.1 \pm 13$ & $23.8 \pm 11$ & NS \\
\hline IL-6 & $10.5 \pm 7.1$ & $10.2 \pm 6.1$ & $12.1 \pm 4.3$ & NS \\
\hline IL-10 & $52.4 \pm 48$ & $76.3 \pm 67$ & $100 \pm 41$ & NS \\
\hline IL-12 (p40) & $138 \pm 55^{\mathrm{a}}$ & $73.8 \pm 42^{\mathrm{b}}$ & $207 \pm 27^{\mathrm{c}}$ & $<0.0001$ \\
\hline IL-12 (p70) & $105 \pm 133$ & $218 \pm 236$ & $271 \pm 128$ & NS \\
\hline IL-17 & $88.1 \pm 69$ & $137 \pm 100$ & $151 \pm 52$ & NS \\
\hline Eotaxin & $941 \pm 789$ & $1449 \pm 774$ & $1048 \pm 673$ & NS \\
\hline G-CSF & $156(62-172)$ & $120(56-170)$ & $131(128-165)$ & NS \\
\hline GM-CSF & $280 \pm 112$ & $239 \pm 102$ & $251 \pm 120$ & NS \\
\hline IFN- $\boldsymbol{\gamma}$ & $20.2 \pm 16$ & $29.8 \pm 33$ & $23.7 \pm 15$ & NS \\
\hline KC & $25.5 \pm 7.9$ & $25.0 \pm 6.2$ & $28.2 \pm 12$ & NS \\
\hline MCP-1 & $88.8 \pm 72$ & $120 \pm 88$ & $143 \pm 63$ & NS \\
\hline MIP-1 $\boldsymbol{\alpha}$ & $45.0 \pm 13$ & $43.7 \pm 37$ & $53.7 \pm 15$ & NS \\
\hline MIP-1 $\boldsymbol{\beta}$ & $32.9 \pm 11$ & $29.8 \pm 20$ & $32.5 \pm 10$ & NS \\
\hline RANTES & $13.5 \pm 5.0^{\mathrm{a}}$ & $14.3 \pm 11^{\mathrm{ab}}$ & $22.8 \pm 1.4^{\mathrm{b}}$ & 0.02 \\
\hline TNF- $\boldsymbol{\alpha}$ & $489 \pm 480$ & $470 \pm 706$ & $816 \pm 361$ & $\mathrm{NS}$ \\
\hline
\end{tabular}

Data are mean $\pm \mathrm{SD}$ or median (IQR). Groups with different letters are significantly different (Tukey's or Games-Howell post hoc).

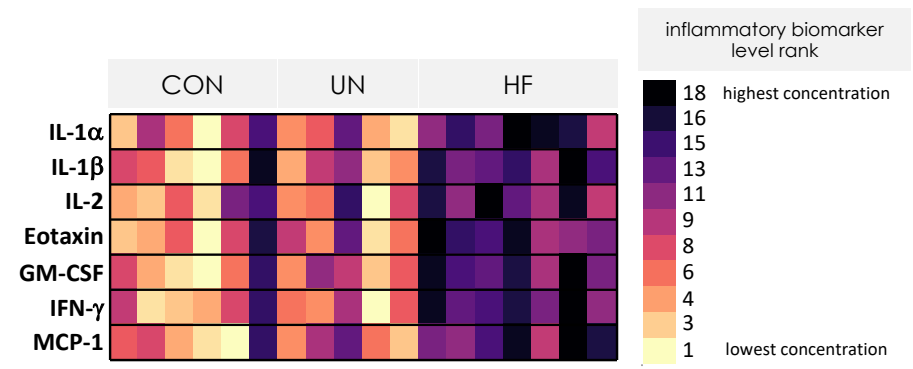

Figure 3. Heatmap of inflammatory biomarker level rank for each of the seven SI IEL biomarkers that were significantly different between dietary groups (refer to Table 1). For each inflammatory biomarker, concentrations were ranked from lowest to highest concentration for all mothers. Rank values ranged from 1 to 18 , where higher values indicate higher concentrations for that inflammatory biomarker in SI IEL.

Expression of Abcb1a and Abcg2 correlates with SI villus proliferation index in UN pregnancies

As we observed the greatest change in the relative proliferation index and MDR transporter mRNA levels in the SI of UN pregnancies, we conducted a correlation analysis between these variables and observed that villus proliferative status was associated with drug transport expression. There was a significant positive relationship between the relative index of proliferation in the villus and Abcbla mRNA expression $(\mathrm{rho}=0.53, \mathrm{p}=0.017$, Figure $6 \mathrm{~A})$, but not in the crypt $(\mathrm{rho}=0.02 ; \mathrm{p}=\mathrm{NS})$. In contrast, there was a significant negative relationship between the relative index of proliferation in the villus and $A b c g 2$ mRNA expression $($ rho $=-0.65, p=0.002$, Figure $6 B)$, but not in the crypt $(r h o=-0.07, p=N S)$. 
bioRxiv preprint doi: https://doi.org/10.1101/2021.10.26.465755; this version posted October 26, 2021. The copyright holder for this preprint (which was not certified by peer review) is the author/funder. All rights reserved. No reuse allowed without permission.

Maternal gut holobiont and malnutrition in pregnancy
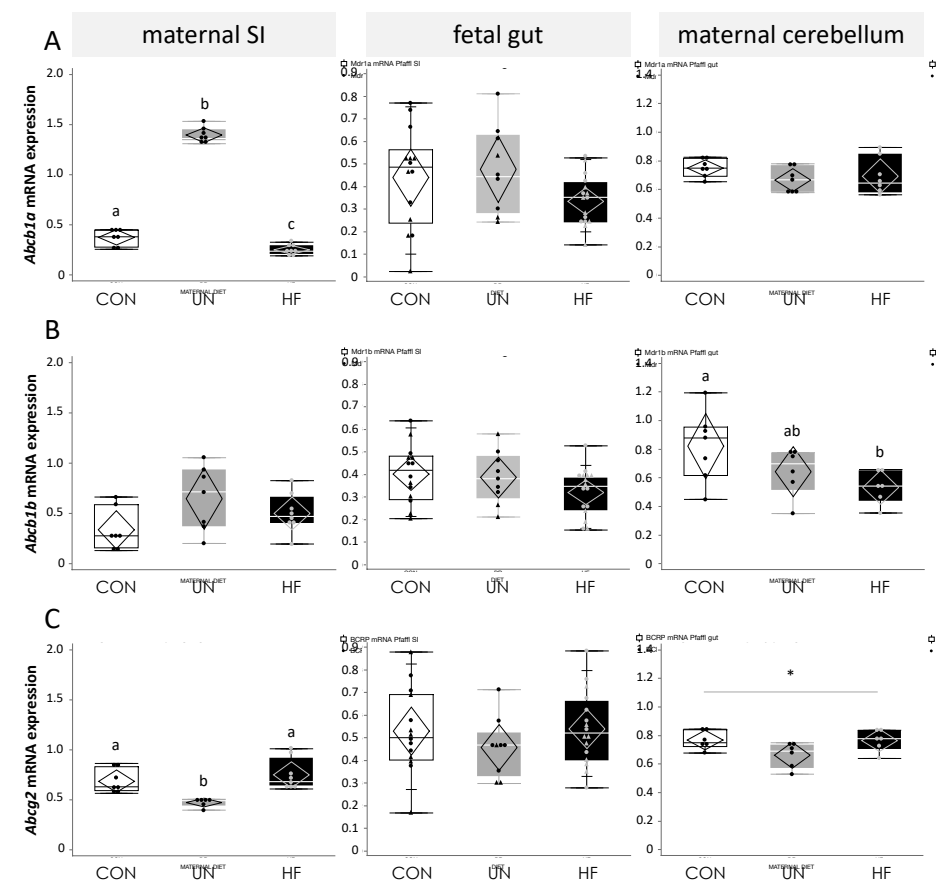

Figure 4. MDR mRNA expression in CON, UN, and HF dams and fetuses at GD18.5. A. Abcbla mRNA expression levels in maternal SI, fetal gut, and maternal cerebellum. B. Abcbl mRNA expression levels in maternal SI, fetal gut, and maternal cerebellum. C. Abcg2 mRNA expression levels in maternal SI, fetal gut, and maternal cerebellum. Data are quantile box plots with $95 \%$ CI confidence diamonds. ${ }^{*} \mathrm{p}<0.05$ (ANOVA). Groups with different letters are significantly different (Games-Howell or Steel-Dwass post hoc).
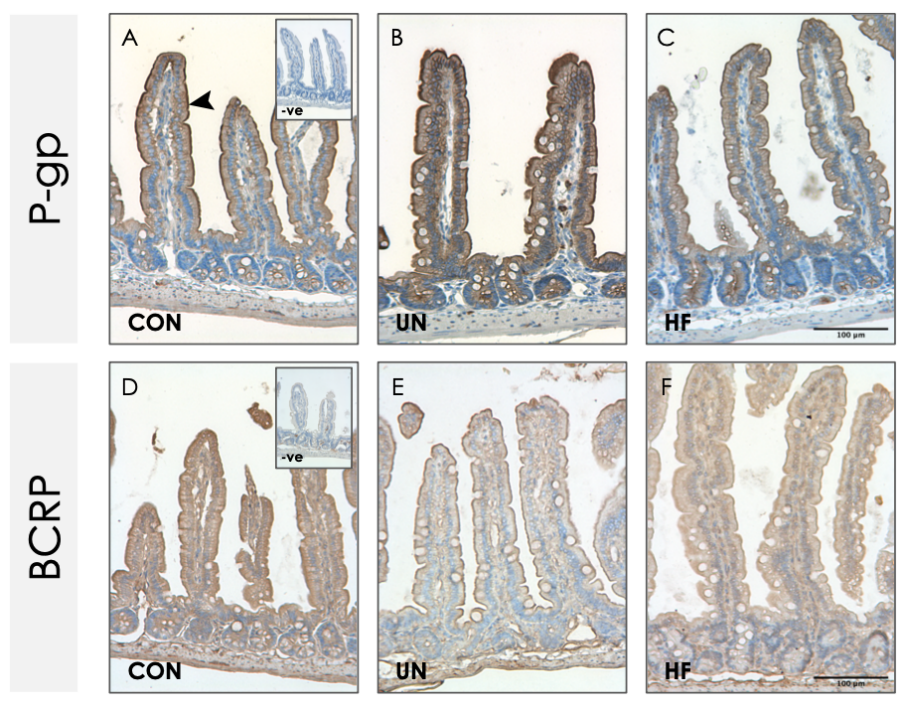

Figure 5. Small intestinal MDR protein expression in CON, UN, and HF dams at GD18.5. Representative images of immunoreactive P-gp (A-C) and BCRP (D-F) staining maternal SI with negative controls (inset). Images captured at $20 \mathrm{X}$ magnification. Scale bar $=100 \mu \mathrm{m}$. Large arrowhead $=$ apical membrane.

Maternal malnutrition alters the gut microenvironment, and these changes are associated with drug transporter expression

Since we previously showed that maternal malnutrition, particularly HF diet, alters the composition of the gut microbiome[35], and herein we observed that maternal malnutrition modulates gut mRNA expression of key MDR transporters, we sought to determine if there were relationships between maternal gut microbiome composition and MDR transporter expression. Inclusive of all diets, we found significant associations between $A b c b 1 a$ and $A b c g 2$ mRNA expression levels with relative abundance of microbial taxa, where the direction of relationship was transporter-dependent. Seven families were significantly positively associated, and seven were significantly negatively associated, with Abcbla mRNA expression levels $(\mathrm{q}<0.05$; Figure $7 \mathrm{~A})$. Three families were significantly positively associated, and six families were significantly negatively associated, with $\mathrm{Abcg} 2 \mathrm{mRNA}$ expression levels $(\mathrm{q}<0.05$; Figure $7 \mathrm{~A})$. At the genus level, four genera were significantly positively associated, and six were significantly negatively associated, with $A b c b 1 a$ mRNA expression levels $(\mathrm{q}<0.05$; Figure $7 \mathrm{~B})$. Two genera each were significantly positively and negatively associated with $\mathrm{Abcg} 2$ mRNA expression levels $(\mathrm{q}<0.05$; Figure $7 \mathrm{~B})$. The relative abundance level of one species, Clostridium septicum, was negatively associated with SI $A b c b 1 a$ mRNA expression levels ( $\mathrm{rho}=-0.81$; $\mathrm{q}<0.0004$; Figure 8A). Additionally, $C$. septicum relative abundance levels were significantly reduced in $\mathrm{UN}$ mothers compared to $\mathrm{CON}$ and $\mathrm{HF}(\mathrm{p}=0.006$; Figure 8B). There were no significant associations between Abcg2 mRNA expression levels and species relative abundance levels within the whole cohort. However, diet-stratified analyses identified one classified species, Trichodesmium erythraeum, whose relative abundance level was positively associated with SI Abcg2 mRNA expression levels in HF mothers (rho=1; $\mathrm{q}=0.005$; Figure $8 \mathrm{~A}$ shows relationship in all mothers). Moreover, relative abundance levels of this species were significantly reduced in HF-fed mothers compared to $\mathrm{CON}$ and $\mathrm{UN}$ ( $\mathrm{p}=0.004$; Figure 8B).
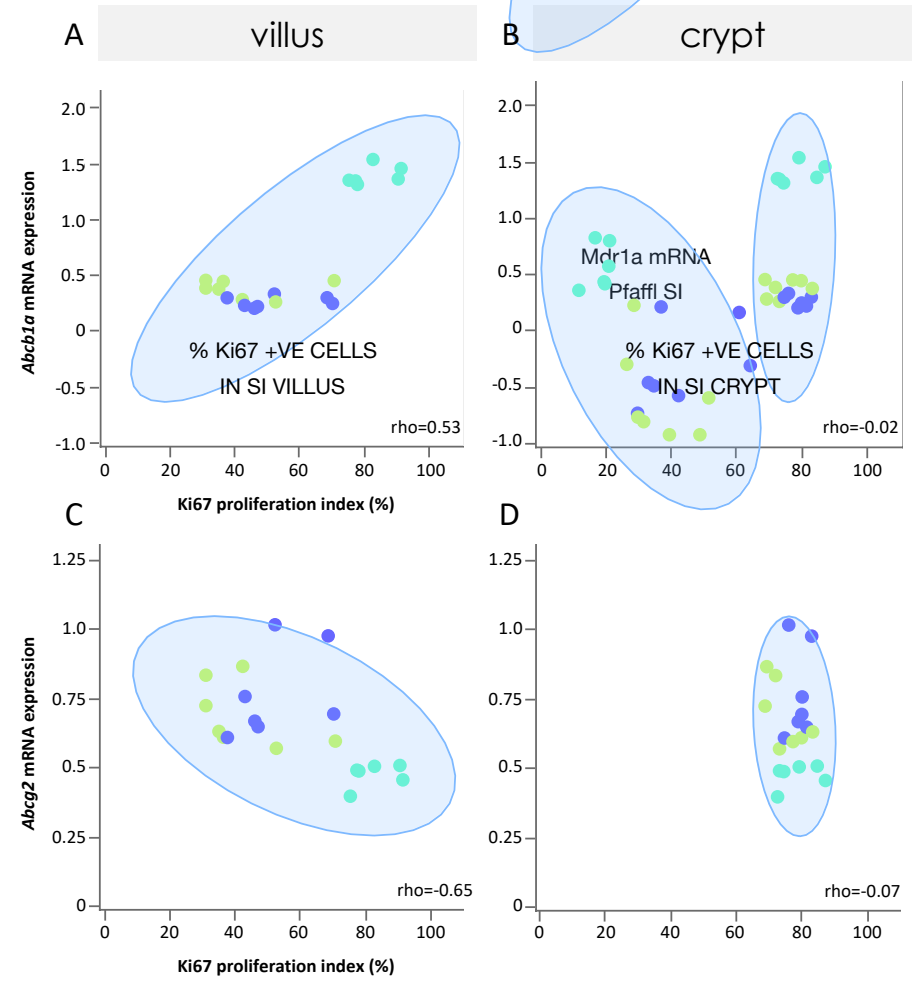

Figure 6. Relationships between relative index of proliferation in maternal villi and crypts with $A b c b 1 a(\mathrm{~A}, \mathrm{~B})$ and $\operatorname{Abcg} 2$ (C, D) mRNA expression levels, inclusive of all diets. Yellow circles $=\mathrm{CON}$, blue circles $=\mathrm{HF}$, green circles $=$ UN. 95\% density ellipses shown in light blue. $\mathrm{p}<0.05$ (Spearman's rho). 
Maternal gut holobiont and malnutrition in pregnancy

A

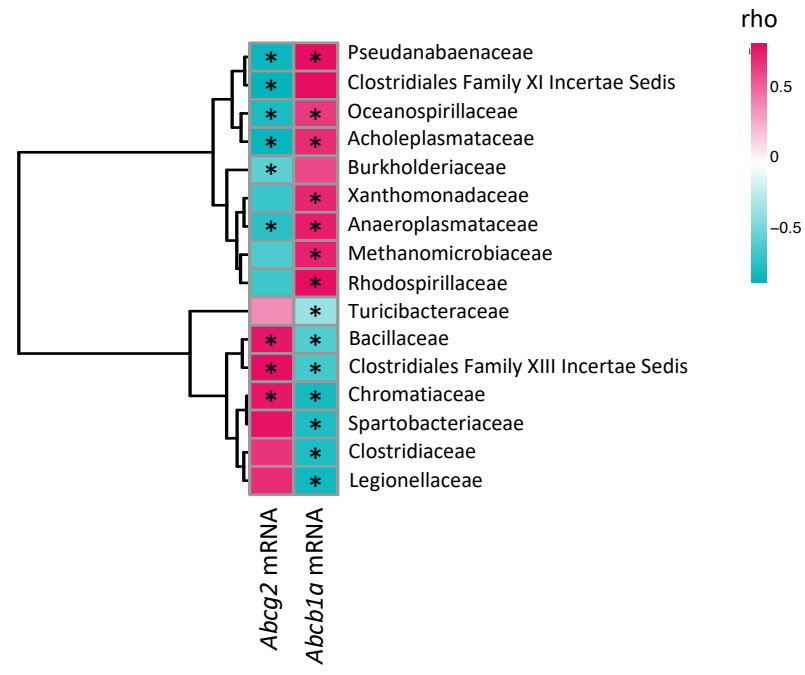

B

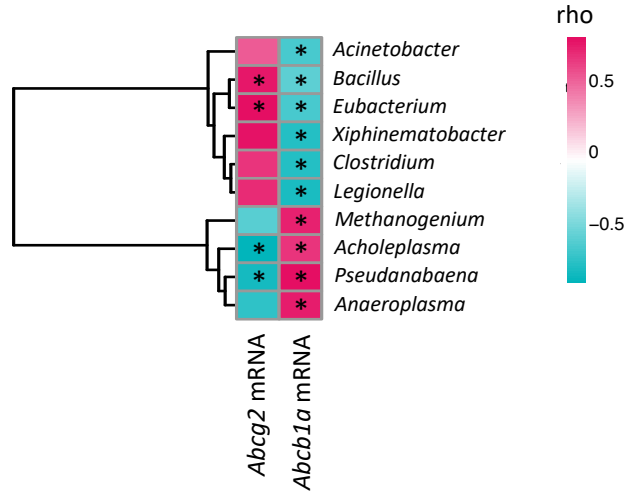

Figure 7. Associations between maternal gut microbial taxa relative abundance at the family (A) and genus (B) levels with efflux transporter mRNA expression levels. Red indicates a positive association, blue indicates a negative association. Colour saturation indicates the strength of relationship. * indicates significant association $(\mathrm{q}<0.05)$. See Tables A. 3 and A.4 for details.

Maternal diet coordinates the gut holobiome and microenvironment Principal component analysis revealed that mothers could be discriminated based on their nutritional history when assessing key features contributing to variation in gut homeostasis (gut microbiome dissimilarity, small intestinal inflammatory load and proliferation, and expression levels of MDR transporters). Distinct clusters of mothers emerged primarily based on PC1 (Figure 9). All features were considered important for PC1 (eigenvalue [EV] 2.69, explaining 53.8\% of variance in the data, Figure 9 and Figure A.1). Based on PC2, the features with the greatest EVs were represented by gut microbiome dissimilarity, SI IEL inflammatory load, and Ki67 proliferation index in villi (EV 1.24, explaining $24.9 \%$ of variance in the data, Figure 9 and Figure A.1). Collectively, PCA revealed that mothers with similar holobionts and gut microenvironments clustered together, and clustering was largely determined by nutritional history.

\section{Discussion}

Here, we report that maternal diet provokes adaptations in the pregnancy holobiont, improving our understanding of how common nutritional adversities impact maternal gut homeostasis and the mechanisms that contribute to reprogramming the normal course of fetal development. Using a systems physiology approach we identified that malnutrition alters SI architecture and villi proliferation, pro-inflammatory load, and expression of $\mathrm{P}-\mathrm{gp} / A b c b 1 a$ and $\mathrm{BCRP} / A b c g 2$, key MDR transport systems in pregnancy. We also report significant associations between
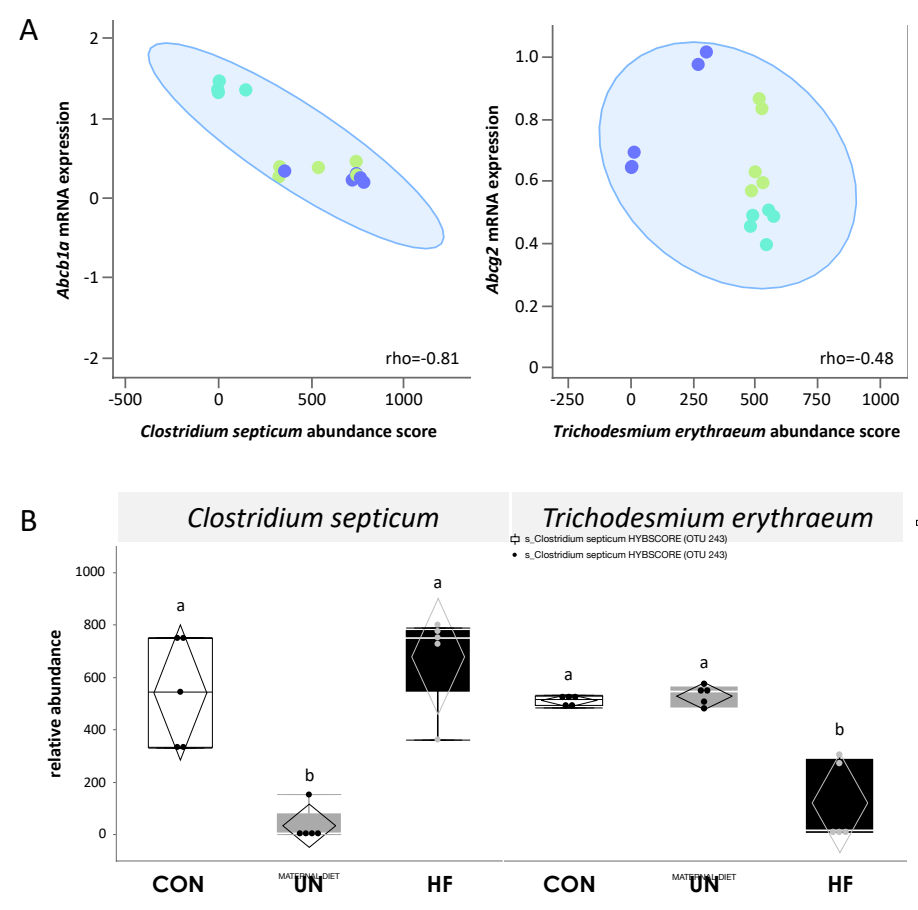

Figure 8. Bacterial species associated with SI MDR mRNA expression. A. Relationships between species relative abundance and $A b c b 1 a$ or $A b c g 2$ mRNA expression levels in all mothers. Yellow circles $=\mathrm{CON}$, blue circles $=\mathrm{HF}$, green circles $=\mathrm{UN}$. 95\% density ellipses shown in light blue. $\mathrm{q}<0.05$ (Spearman's rho). T. erythraeum relative abundance was positively associated with $A b c g 2$ mRNA levels in HF mothers $(q=0.005)$. B. Relative abundance levels of $C$. septicum and T. erythraeum in maternal caecal contents at GD18.5. Data are quantile box plots with $95 \%$ CI confidence diamonds. ${ }^{*} \mathrm{p}<0.05$ (ANOVA). Groups with different letters are significantly different (Steel-Dwass or Games-Howell post hoc).

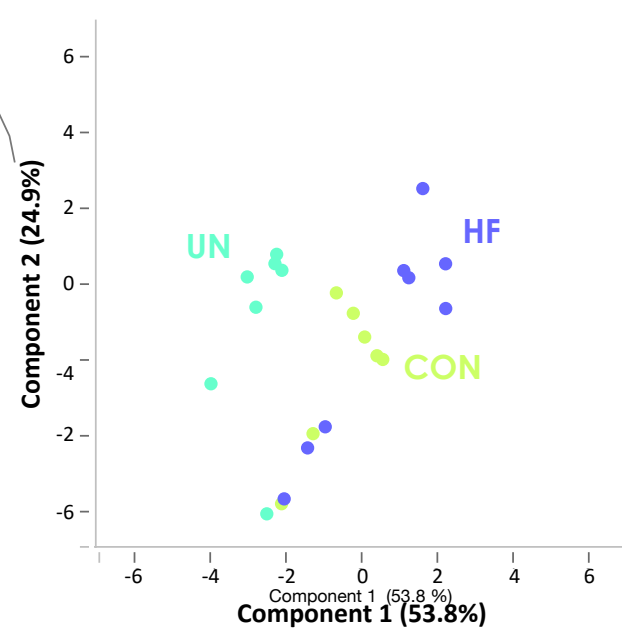

Figure 9. Maternal diet coordinates gut allostasis. PCA of features contributing to maternal gut allostasis. Percent variation explained by the principle components is indicated in parentheses on the $\mathrm{x}$ - and $\mathrm{y}$-axes. 
Abcbla and Abcg2 mRNA levels with relative abundance of specific microbial taxa, and that features of the gut microenvironment are largely determined by maternal diet.

We provide the first report of diet-induced changes in MDR transporters in the maternal SI during pregnancy, and their relationships with the gut microbiome. Whilst it is well known that physiologic changes due to pregnancy[46], and malnutrition[24] or metabolic disease[25, 26] in the non-pregnant state, affect drug disposition, to date, few studies have explored how maternal gut MDR transport adapts to dietary challenges that influence pregnancy phenotype. Consistent with our mRNA and immunoreactivity findings, a study in non-pregnant mice using a similar degree of caloric restriction as reported here, found increased $A b c b 1 a$ mRNA expression in the duodenum and jejunum of calorically-restricted mice, with the most striking increase in expression in the jejunum[24]. Pgp activity was also shown to be increased in these mice[24]. In contrast, Abcbla mRNA expression was lower in HF mothers in our study, with levels consistent with lower Abcbla expression we have reported in HF placentae[3]. Non-pregnant mice genetically resistant to diet-induced obesity and lacking P-gp have increased body weight, altered glucose control and dysfunctional lipid homeostasis, phenotypes that can be further exacerbated by feeding a HF diet[47], suggesting a permissive role for P-gp in obesity and metabolic dysfunction. Our HF-fed mothers have metabolic dysfunction [3, 35], but it is unclear if this is permissive of, or related to, disrupted intestinal P-gp. We also report lower Abcg2 mRNA expression and immunoreactivity in SI of UN mothers, consistent with changes in placentae from UN mothers[3] and from pregnancies complicated by intrauterine growth restriction[48]. Conversely, we did not observe any changes in $A b c g 2$ expression in SI of HF mothers, despite that BCRP expression has been reported to be lower in the SI mucosa of HF-fed non-pregnant mice[49], highlighting that pregnancy may impact $A b c g 2$ SI responsiveness to maternal malnutrition. Importantly, studies in rodents have shown that site-specific mRNA expression levels of P-gp and BCRP are good correlates with protein expression[19]. P-gp substrates include antibiotics (amoxicillin, clarithromycin, ciprofloxacin, levofloxacin, rifampicin, tetracycline), antiretrovirals (indinavir, saquinavir, ritonavir, nelfinavir), antifungals (itraconazole), stomachprotective drugs (cimetidine, ranitidine), nonsteroidal anti-inflammatory drugs (NSAIDs; diclofenac), synthetic glucocorticoids (dexamethasone prednisolone), cytokines (IL-6; IFN- $\gamma ;$ TNF- $\alpha$ ) and nutrients (flavonoids), and BCRP substrates include antibiotics (beta-lactams, fluoroquinolones), antiretrovirals (indinavir, zidovudine), sulfonylureas (glyburide) and nutrients (folate)[22]. Modulation of these transporters in the maternal gut by diet can alter the local and systemic levels of their substrates. Thus, our findings suggest there may be implications not only for the availability and biodisposition of drugs, but also nutrients and inflammatory molecules, and thus potential fetal exposure to these, if the mother is malnourished.

The cellular and molecular mechanisms explaining how malnutrition alters MDR expression in pregnancy are unclear. To address this, we first explored whether and how maternal gut morphology adapts to the spectrum of malnutrition, as intestinal architecture and morphology may influence cellular function. We observed a greater crypt depth in SI from HF mothers compared to CON. Crypt hyperplasia, hallmarked by an elongated crypt due to an increase in the number of epithelial cells, is one defining feature of intestinal inflammation[50]. Whilst we did not observe an increase in the proliferative index of HF SI compared to CON, we did show an increase in the levels of seven pro-inflammatory biomarkers in SI IEL, specific to HF pregnancies. Intestinal IELs are considered to be gut sentinels, which effectively contribute to the maintenance of mucosal barrier integrity in part through their production of a number of cytokines that regulate intestinal barrier homeostasis[51]. When dysregulated, IELs may promote the onset of gut and systemic pathologies[52]. In Mdrla ${ }^{\%}$ mice, HF diet worsens spontaneous inflammatory bowel disease and histologic pathologies, including elongation of crypts[38]. Notably, $A B C B 1 / \mathrm{P}$-gp expression levels are lower in inflamed intestinal epithelia of patients with gastrointestinal diseases (vs. uninflamed intestinal epithelia), and in vitro, lower $A B C B 1$ expression has been observed with higher levels of cytokines[53]. Thus, the pro-inflammatory environment established by HF feeding may contribute to a downregulation of Abcbal expression in our model, and this reduction in expression, if followed by reduced P-gp function, may eventuate in susceptibility to gastrointestinal dysfunction and compromised tissue defences, with implications for the health of the pregnancy and fetus. This would be consistent with the observed altered expression or activity of these MDRs in the yolk sac, placenta and fetal blood brain barrier in the presence of bacterial and viral infection[54-56] including malaria[57], resulting in increased fetoplacental substrate accumulation, altered fetal growth, or preterm delivery.

In contrast to the HF diet, the villus appeared impacted by maternal UN. We observed increased proliferation in UN SI, consistent with other caloric restriction studies in the non-pregnant host[58]. Increased proliferation in villi is an adaptation aimed to improve the absorptive capacity of the intestine, particularly in an effort to sequester more nutrients when bodyweight decreases[58]. It stands then that other transporters, including MDRs, may also increase their expression/function in a similar manner. Although we have no direct measure of function, we determined that there was a positive relationship between villus proliferation index and $A b c b 1 a$ mRNA expression, largely driven by maternal $\mathrm{UN}$, and a negative relationship between villus proliferation index and $\mathrm{Abcg} 2 \mathrm{mRNA}$ expression. Future studies using single cell analysis could help to determine whether changes in transporter expression levels or activity are a function of the number of cells present. Still, these findings are consistent with studies that show targeted silencing of $A B C B 1$ results in reduced cell proliferation and invasion in human extravillous trophoblast (EVT)[59], and BCRP inhibits EVT cell migration[60], whilst P-gp overexpression in fibroblasts accelerates cell proliferation and migration[61]. Therefore, MDR expression may play a key role not only in substrate transport dynamics, but also maintenance of key barrier tissues, especially those that are rapidly developing or turning over. Altered cellular proliferation and migration may indirectly alter the absorption and excretion of important pharmacological and physiological substrates during reproduction and pregnancy. Additionally, of importance, we did not observe any changes in fetal gut mRNA expression of these MDRs. This, in consideration with our previous findings of altered placental $A b c b l a$ and Abcg2 mRNA expression in placentae from malnourished mothers[3], suggests that fetal gut MDR is not programmed by maternal diet in term pregnancies, although altered maternal gut and placental MDR expression and function could contribute to fetal maldevelopment independent of changes in fetal gut MDRs, through changes in transport and bioavailability of P-gp and BCRP substrates.

To further understand possible mechanisms underlying the observed changes in intestinal allostasis, we next explored whether there were relationships between maternal SI MDR expression levels and gut bacteria. MDRs are ideally localised[19-21] (at the enterocyte apical membrane) to play key roles in host-microbe interactions in the gut, although beyond pathogenic bacteria[62, 63], whether there is a functional consequence of microbial-MDR cross talk is not known. Here we provide the first report of relationships between SI MDR transporters and microbial relative abundance levels in malnourished pregnancies. 
We found significant associations between relative abundance levels of specific taxa and expression of $A b c b l a$ and $A b c g 2$, including a negative association between $C$. septicum, a Gram-positive spore-forming bacillus in the human and animal GI tract[64], and Abcbla. When exploring these relationships more closely relative to maternal diet, we found the relative abundance of this species was lower in UN mothers compared to CON and HF. Members of the Clostridia class have key roles in gut homeostasis and maintenance of mucous production by the host[65-67], and have recently been shown to correlate with colonic P-gp expression in mice[68]. We previously found increased goblet cell number in UN maternal SI[34], which collectively with higher Abcbla expression, may suggest a beneficial adaptation of the UN gut to increase intestinal defences, including to potentially harmful microbes or their metabolites. In contrast, $A b c g 2$ expression was positively associated with relative abundance levels of T. erythraeum, but in HF mothers only, where abundance levels were significantly reduced compared to CON and UN. We previously reported relationships between $T$. erythraeum relative abundance levels and concentrations of maternal circulating inflammatory and metabolic biomarkers[35], and noted that although little is known about this species in the context of mammalian health, it is important for iron storage[69] and DNA protection against oxidative stress [70, 71] . BCRP/Abcg2 can efflux porphyrin/haem in an effort to tightly regulate iron availability for host cellular metabolism and prevent toxicity[72, 73]. Abundance levels of microbes will be influenced by iron availability, in part determined by mechanisms that regulate host iron biodisposition, including efflux transport. It is also plausible that gut microbes or their metabolites could directly influence these mechanisms. For example, mice lacking a gut microbiome significantly increase intestinal iron absorption via actions of microbial metabolites on HIF$2 \alpha[74]$, and microbial production of butyrate and secondary bile acids potentiates P-gp expression in colonic epithelium[68]. Clearly in the gut there is tight regulation between nutrient levels and the presence and function of microbes, and gut MDR expression. Future studies should build on this knowledge and directly test how gut microbes and their metabolites regulate intestinal MDRs in pregnancy under basal and challenged conditions, including poor nutrition. The MDR-microbe interactions may be key to preventing bioaccumulation or extrusion of many substances, including microbial metabolites, that can result in cellular toxicity and disruption of the maternal intestinal barrier, and may be especially important cross-talks to maintain in pregnancies with an already imbalanced gut holobiont. Indeed our PCA analyses showed that nutritional history largely determined how similar mothers were with respect to their holobionts and gut microenvironments.

A limitation of our study is that we did not measure the SI microbiome, but suggest that the caecal microbiome can inform about SI function. There is limited understanding of the human and mouse SI microbiomes, including how microbes residing in the SI may influence key physiological functions in their niche, such as nutrient metabolism or epithelial defences. Mice are coprophagic, and a series of elegant studies showed that this behaviour alters the SI microbial load and composition and function of the SI microbiome, with limited or no effects in the lower gastrointestinal tract[75]. Further, coprophagic mice have SI and stomach microbiomes that are compositionally more similar to caecal microbiomes than non-coprophagic mice[75]. Studies have shown that the relative abundance of major phyla in the mouse SI, colon and caecum are similar, but there are genera exclusive to each niche[76, 77]. We believe sampling the caecal contents can provide a reasonable picture of gut microbial changes to environmental conditions[78], including diet, that cannot easily be ascertained from limited samples in the upper gastrointestinal tract. Future studies should consider the role of coprophagy and the SI microbiome on host response to malnutrition[79].
Our study identifies adaptations in the pregnancy gut holobiont to dietary challenge that could affect pregnancy health and contribute to fetal maldevelopment. We suggest attempts to improve outcomes for pregnancies and offspring exposed to adverse dietary conditions have only partially been successful due to the complexity of interactions between the environment, host, and its resident microbes. Here we took a systems physiology approach to better understand these relationships, and propose that gut holobiont dysfunction and diet-MDR - microbe interactions may be key targets for improving reproductive and pregnancy health, particularly in mothers with an already imbalanced gut holobiont.

\section{Acknowledgments}

The authors wish to thank Ela Matysiak and Richard Maganga for their assistance with the animal cohort and Adam Altrichter for his assistance with the microbiome analyses.

\section{Author Contributions}

Conceptualisation, KLC, SJL, EB; data acquisition/analysis KLC, EB, TZD; writing/revising KLC, EB, SJL, TZD.

\section{Funding}

This research was funded by the Canadian Institutes of Health Research (CIHR) (grants MOP-81238 and FDN-143262 to SJL and Fellowship MFE-246638 to KLC). KLC is supported by the CIHR, the Natural Sciences and Engineering Research Council of Canada, the Molly Towell Perinatal Research Foundation (New Investigator), and Carleton University Office of Research. EB is supported by the Conselho Nacional de Desenvolvimento Científico e Tecnológico (CNPq, 310578/2020-5).

The authors have no competing interests and nothing to disclose. Data are available upon reasonable request.

\section{Supplementary files}

This article contains supplemental figures and tables, which can be found at the end of this document. 
bioRxiv preprint doi: https://doi.org/10.1101/2021.10.26.465755; this version posted October 26, 2021. The copyright holder for this preprint (which was not certified by peer review) is the author/funder. All rights reserved. No reuse allowed without permission.

Maternal gut holobiont and malnutrition in pregnancy

\section{References}

[1] Jansson N, Nilsfelt A, Gellerstedt M, Wennergren M, RossanderHulthen L, Powell TL, et al. Maternal hormones linking maternal body mass index and dietary intake to birth weight. Am J Clin Nutr. 2008;87:1743-9.

[2] Mahajan SD, Singh S, Shah P, Gupta N, Kochupillai N. Effect of maternal malnutrition and anemia on the endocrine regulation of fetal growth. Endocr Res. 2004;30:189-203.

[3] Connor KL, Kibschull M, Matysiak-Zablocki E, Nguyen TTN, Matthews SG, Lye SJ, et al. Maternal malnutrition impacts placental morphology and transporter expression: an origin for poor offspring growth. J Nutr Biochem. 2020;78:108329.

[4] Barbeito-Andres J, Pezzuto P, Higa LM, Dias AA, Vasconcelos JM, Santos TMP, et al. Congenital Zika syndrome is associated with maternal protein malnutrition. Sci Adv. 2020;6:eaaw6284.

[5] Katona $P$, Katona-Apte J. The interaction between nutrition and infection. Clin Infect Dis. 2008;46:1582-8.

[6] Aye IL, Lager S, Ramirez VI, Gaccioli F, Dudley DJ, Jansson T, et al. Increasing maternal body mass index is associated with systemic inflammation in the mother and the activation of distinct placental inflammatory pathways. Biol Reprod. 2014;90:129.

[7] Kesavan K, Devaskar SU. Intrauterine Growth Restriction: Postnatal Monitoring and Outcomes. Pediatr Clin North Am. 2019;66:403-23.

[8] Black RE, Victora CG, Walker SP, Bhutta ZA, Christian P, de Onis M, et al. Maternal and child undernutrition and overweight in low-income and middle-income countries. Lancet. 2013;382:427-51.

[9] NCD Risk Factor Collaboration. Worldwide trends in body-mass index, underweight, overweight, and obesity from 1975 to 2016: a pooled analysis of 2416 population-based measurement studies in 128.9 million children, adolescents, and adults. Lancet. 2017;390:2627-42.

[10] Jarman M, Yuan Y, Pakseresht M, Shi Q, Robson PJ, Bell RC. Patterns and trajectories of gestational weight gain: a prospective cohort study. CMAJ Open. 2016;4:E338-45.

[11] Popkin BM, Adair LS, Ng SW. Global nutrition transition and the pandemic of obesity in developing countries. Nutr Rev. 2012;70:3-21.

[12] Attia S, Feenstra M, Swain N, Cuesta M, Bandsma RHJ. Starved Guts: Morphologic and Functional Intestinal Changes in Malnutrition. J Pediatr Gastroenterol Nutr. 2017;65:491-5.

[13] Riva A, Kuzyk O, Forsberg E, Siuzdak G, Pfann C, Herbold C, et al. A fiber-deprived diet disturbs the fine-scale spatial architecture of the murine colon microbiome. Nat Commun. 2019;10:4366.

[14] Genton L, Cani PD, Schrenzel J. Alterations of gut barrier and gut microbiota in food restriction, food deprivation and protein-energy wasting. Clin Nutr. 2015;34:341-9.

[15] Araujo JR, Tomas J, Brenner C, Sansonetti PJ. Impact of high-fat diet on the intestinal microbiota and small intestinal physiology before and after the onset of obesity. Biochimie. 2017;141:97-106.

[16] Kong S, Zhang YH, Zhang W. Regulation of Intestinal Epithelial Cells Properties and Functions by Amino Acids. Biomed Res Int. 2018;2018:2819154.

[17] Allaire JM, Crowley SM, Law HT, Chang SY, Ko HJ, Vallance BA. The Intestinal Epithelium: Central Coordinator of Mucosal Immunity. Trends Immunol. 2018;39:677-96.

[18] Mercado-Lubo R, McCormick BA. The interaction of gut microbes with host ABC transporters. Gut Microbes. 2010;1:301-6.

[19] MacLean C, Moenning U, Reichel A, Fricker G. Closing the gaps: a full scan of the intestinal expression of p-glycoprotein, breast cancer resistance protein, and multidrug resistance-associated protein 2 in male and female rats. Drug Metab Dispos. 2008;36:1249-54.

[20] Maliepaard M, Scheffer GL, Faneyte IF, van Gastelen MA, Pijnenborg $A C$, Schinkel $A H$, et al. Subcellular localization and distribution of the breast cancer resistance protein transporter in normal human tissues. Cancer Res. 2001;61:3458-64.
[21] Thiebaut F, Tsuruo T, Hamada H, Gottesman MM, Pastan I, Willingham MC. Cellular localization of the multidrug-resistance gene product $\mathrm{P}$-glycoprotein in normal human tissues. Proc Natl Acad Sci U S A. 1987;84:7735-8.

[22] Bloise E, Ortiga-Carvalho TM, Reis FM, Lye SJ, Gibb W, Matthews SG. ATP-binding cassette transporters in reproduction: a new frontier. Hum Reprod Update. 2016;22:164-81.

[23] Fricker G, Miller DS. Relevance of multidrug resistance proteins for intestinal drug absorption in vitro and in vivo. Pharmacol Toxicol. 2002;90:5-13.

[24] Renaud HJ, Klaassen CD, Csanaky IL. Calorie Restriction Increases P-Glycoprotein and Decreases Intestinal Absorption of Digoxin in Mice. Drug Metab Dispos. 2016;44:366-9.

[25] Zhang LL, Lu L, Jin S, Jing XY, Yao D, Hu N, et al. Tissue-specific alterations in expression and function of P-glycoprotein in streptozotocin-induced diabetic rats. Acta Pharmacol Sin. 2011;32:956-66.

[26] Wang Z, Yang H, Xu J, Zhao K, Chen Y, Liang L, et al. Prediction of Atorvastatin Pharmacokinetics in High-Fat Diet and Low-Dose Streptozotocin-Induced Diabetic Rats Using a Semiphysiologically Based Pharmacokinetic Model Involving Both Enzymes and Transporters. Drug Metab Dispos. 2019;47:1066-79.

[27] Bordenstein SR, Theis KR. Host Biology in Light of the Microbiome: Ten Principles of Holobionts and Hologenomes. PLoS Biol. 2015;13:e1002226.

[28] Rastelli M, Cani PD, Knauf C. The Gut Microbiome Influences Host Endocrine Functions. Endocr Rev. 2019;40:1271-84.

[29] Visconti A, Le Roy Cl, Rosa F, Rossi N, Martin TC, Mohney RP, et al. Interplay between the human gut microbiome and host metabolism. Nat Commun. 2019;10:4505.

[30] Cryan JF, O'Riordan KJ, Cowan CSM, Sandhu KV, Bastiaanssen TFS, Boehme $M$, et al. The Microbiota-Gut-Brain Axis. Physiol Rev. 2019;99:1877-2013.

[31] Vuong HE, Pronovost GN, Williams DW, Coley EJL, Siegler EL, Qu $A$, et al. The maternal microbiome modulates fetal neurodevelopment in mice. Nature. 2020.

[32] Chen X, Li P, Liu M, Zheng H, He Y, Chen MX, et al. Gut dysbiosis induces the development of pre-eclampsia through bacterial translocation. Gut. 2020;69:513-22.

[33] Shimizu M. Interaction between food substances and the intestinal epithelium. Biosci Biotechnol Biochem. 2010;74:232-41.

[34] Srugo SA, Bloise E, Nguyen TTN, Connor KL. Impact of Maternal Malnutrition on Gut Barrier Defense: Implications for Pregnancy Health and Fetal Development. Nutrients. 2019;11.

[35] Connor KL, Chehoud C, Altrichter A, Chan L, DeSantis TZ, Lye SJ. Maternal metabolic, immune, and microbial systems in late pregnancy vary with malnutrition in mice. Biol Reprod. 2018.

[36] Catalioto RM, Maggi CA, Giuliani S. Intestinal epithelial barrier dysfunction in disease and possible therapeutical interventions. Curr Med Chem. 2011;18:398-426.

[37] Lefrancois L, Lycke N. Isolation of mouse small intestinal intraepithelial lymphocytes, Peyer's patch, and lamina propria cells. Curr Protoc Immunol. 2001; Chapter 3:Unit 319.

[38] Paik J, Fierce Y, Treuting PM, Brabb T, Maggio-Price L. High-fat dietinduced obesity exacerbates inflammatory bowel disease in genetically susceptible Mdr1a-/- male mice. J Nutr. 2013;143:1240-7.

[39] Gulhane M, Murray L, Lourie R, Tong H, Sheng YH, Wang R, et al. High Fat Diets Induce Colonic Epithelial Cell Stress and Inflammation that is Reversed by IL-22. Sci Rep. 2016;6:28990.

[40] Beuling E, Baffour-Awuah NY, Stapleton KA, Aronson BE, Noah TK, Shroyer NF, et al. GATA factors regulate proliferation, differentiation, and gene expression in small intestine of mature mice. Gastroenterology. 2011;140:1219-29 e1-2. 
bioRxiv preprint doi: https://doi.org/10.1101/2021.10.26.465755; this version posted October 26, 2021. The copyright holder for this preprint (which was not certified by peer review) is the author/funder. All rights reserved. No reuse allowed without permission.

Maternal gut holobiont and malnutrition in pregnancy

[41] Burcombe R, Wilson GD, Dowsett M, Khan I, Richman PI, Daley F, et al. Evaluation of Ki-67 proliferation and apoptotic index before, during and after neoadjuvant chemotherapy for primary breast cancer. Breast Cancer Res. 2006;8:R31.

[42] Bloise E, Couto HL, Massai L, Ciarmela P, Mencarelli M, Borges LE, et al. Differential expression of follistatin and FLRG in human breast proliferative disorders. BMC Cancer. 2009;9:320.

[43] Pfaffl MW. A new mathematical model for relative quantification in realtime RT-PCR. Nucleic Acids Res. 2001;29:e45.

[44] Probst AJ, Weinmaier T, DeSantis TZ, Santo Domingo JW, Ashbolt N. New perspectives on microbial community distortion after wholegenome amplification. PLoS One. 2015;10:e0124158.

[45] Probst AJ, Y. LP, B. J, Dubinsky EA, Piceno YM, Tom LM, et al. Microarray of $16 S$ rRNA gene probes for quantifying population differences across microbiome samples. In: He Z, editor. Microarrays Current Technology, Innovations and Applications. Norfolk: Caister Academic Press; 2014.

[46] Pariente G, Leibson T, Carls A, Adams-Webber T, Ito S, Koren G. Pregnancy-Associated Changes in Pharmacokinetics: A Systematic Review. PLoS Med. 2016;13:e1002160.

[47] Foucaud-Vignault M, Soayfane Z, Menez C, Bertrand-Michel J, Martin PG, Guillou H, et al. P-glycoprotein dysfunction contributes to hepatic steatosis and obesity in mice. PLoS One. 2011;6:e23614.

[48] Evseenko DA, Murthi P, Paxton JW, Reid G, Emerald BS, Mohankumar KM, et al. The ABC transporter BCRP/ABCG2 is a placental survival factor, and its expression is reduced in idiopathic human fetal growth restriction. Faseb J. 2007;21:3592-605.

[49] Wisniewski JR, Friedrich A, Keller T, Mann M, Koepsell H. The impact of high-fat diet on metabolism and immune defense in small intestine mucosa. J Proteome Res. 2015;14:353-65.

[50] Erben U, Loddenkemper C, Doerfel K, Spieckermann S, Haller D, Heimesaat MM, et al. A guide to histomorphological evaluation of intestinal inflammation in mouse models. Int $\mathrm{J}$ Clin Exp Pathol. 2014;7:4557-76.

[51] Qiu Y, Yang H. Effects of intraepithelial lymphocyte-derived cytokines on intestinal mucosal barrier function. J Interferon Cytokine Res. 2013;33:551-62.

[52] Olivares-Villagomez D, Van Kaer L. Intestinal Intraepithelial Lymphocytes: Sentinels of the Mucosal Barrier. Trends Immunol. 2018;39:264-75.

[53] Blokzijl H, Vander Borght S, Bok LI, Libbrecht L, Geuken M, van den Heuvel FA, et al. Decreased P-glycoprotein (P-gp/MDR1) expression in inflamed human intestinal epithelium is independent of PXR protein levels. Inflamm Bowel Dis. 2007;13:710-20.

[54] Bloise E, Bhuiyan M, Audette MC, Petropoulos S, Javam M, Gibb W, et al. Prenatal endotoxemia and placental drug transport in the mouse: placental size-specific effects. PLoS One. 2013;8:e65728.

[55] Lye P, Bloise E, Javam M, Gibb W, Lye SJ, Matthews SG. Impact of bacterial and viral challenge on multidrug resistance in first- and thirdtrimester human placenta. Am J Pathol. 2015;185:1666-75.

[56] Bloise E, Petropoulos S, Iqbal M, Kostaki A, Ortiga-Carvalho TM, Gibb W, et al. Acute Effects of Viral Exposure on P-Glycoprotein Function in the Mouse Fetal Blood-Brain Barrier. Cell Physiol Biochem. 2017; 41:1044-50.

[57] Martinelli LM, Fontes KN, Reginatto MW, Andrade CBV, Monteiro VRS, Gomes HR, et al. Malaria in pregnancy regulates P-glycoprotein (P-gp/Abcb1a) and ABCA1 efflux transporters in the Mouse Visceral Yolk Sac. J Cell Mol Med. 2020;24:10636-47.

[58] Ferraris RP. Effect of aging and caloric restriction on intestinal sugar and amino acid transport. Front Biosci. 1997;2:e108-15.

[59] Dunk CE, Pappas JJ, Lye P, Kibschull M, Javam M, Bloise E, et al. PGlycoprotein (P-gp)/ABCB1 plays a functional role in extravillous trophoblast (EVT) invasion and is decreased in the pre-eclamptic placenta. J Cell Mol Med. 2018;22:5378-93.
[60] Lye P, Bloise E, Nadeem L, Peng C, Gibb W, Ortiga-Carvalho TM, et al. Breast Cancer Resistance Protein (BCRP/ABCG2) Inhibits Extra Villous Trophoblast Migration: The Impact of Bacterial and Viral Infection. Cells. 2019;8.

[61] Deng L, Li Q, Lin G, Huang D, Zeng X, Wang X, et al. P-glycoprotein Mediates Postoperative Peritoneal Adhesion Formation by Enhancing Phosphorylation of the Chloride Channel-3. Theranostics. 2016;6:204-18.

[62] Siccardi D, Mumy KL, Wall DM, Bien JD, McCormick BA. Salmonella enterica serovar Typhimurium modulates P-glycoprotein in the intestinal epithelium. Am J Physiol Gastrointest Liver Physiol. 2008;294:G1392-400.

[63] Ye S, MacEachran DP, Hamilton JW, O'Toole GA, Stanton BA. Chemotoxicity of doxorubicin and surface expression of $\mathrm{P}$ glycoprotein (MDR1) is regulated by the Pseudomonas aeruginosa toxin Cif. Am J Physiol Cell Physiol. 2008;295:C807-18.

[64] Dahmus JD, Kotler DL, Kastenberg DM, Kistler CA. The gut microbiome and colorectal cancer: a review of bacterial pathogenesis. J Gastrointest Oncol. 2018;9:769-77.

[65] Lopetuso LR, Scaldaferri F, Petito V, Gasbarrini A. Commensal Clostridia: leading players in the maintenance of gut homeostasis. Gut Pathog. 2013;5:23.

[66] Nava GM, Friedrichsen HJ, Stappenbeck TS. Spatial organization of intestinal microbiota in the mouse ascending colon. ISME J. 2011;5:627-38.

[67] Macfarlane S, Hopkins MJ, Macfarlane GT. Toxin synthesis and mucin breakdown are related to swarming phenomenon in Clostridium septicum. Infect Immun. 2001;69:1120-6.

[68] Foley SE, Tuohy C, Dunford M, Grey MJ, De Luca H, Cawley C, et al. Gut microbiota regulation of P-glycoprotein in the intestinal epithelium in maintenance of homeostasis. Microbiome. 2021;9:183.

[69] Roe KL, Barbeau K, Mann EL, Haygood MG. Acquisition of iron by Trichodesmium and associated bacteria in culture. Environ Microbiol. 2012;14:1681-95.

[70] Martinez A, Kolter R. Protection of DNA during oxidative stress by the nonspecific DNA-binding protein Dps. J Bacteriol. 1997;179:5188-94.

[71] Castruita M, Saito M, Schottel PC, Elmegreen LA, Myneni S, Stiefel $\mathrm{El}$, et al. Overexpression and characterization of an iron storage and DNA-binding Dps protein from Trichodesmium erythraeum. Appl Environ Microbiol. 2006;72:2918-24.

[72] Krishnamurthy P, Schuetz JD. The ABC transporter Abcg2/Bcrp: role in hypoxia mediated survival. Biometals. 2005;18:349-58.

[73] Latunde-Dada GO, Laftah AH, Masaratana P, McKie AT, Simpson RJ. Expression of ABCG2 (BCRP) in mouse models with enhanced erythropoiesis. Front Pharmacol. 2014;5:135.

[74] Das NK, Schwartz AJ, Barthel G, Inohara N, Liu Q, Sankar A, et al. Microbial Metabolite Signaling Is Required for Systemic Iron Homeostasis. Cell Metab. 2020;31:115-30 e6.

[75] Bogatyrev SR, Rolando JC, Ismagilov RF. Self-reinoculation with fecal flora changes microbiota density and composition leading to an altered bile-acid profile in the mouse small intestine. Microbiome. 2020;8:19.

[76] Gu S, Chen D, Zhang JN, Lv X, Wang K, Duan LP, et al. Bacterial community mapping of the mouse gastrointestinal tract. PLoS One. 2013;8:e74957.

[77] Onishi JC, Campbell S, Moreau M, Patel F, Brooks Al, Zhou YX, et al. Bacterial communities in the small intestine respond differently to those in the caecum and colon in mice fed low- and high-fat diets. Microbiology (Reading). 2017;163:1189-97.

[78] Ericsson AC, Gagliardi J, Bouhan D, Spollen WG, Givan SA, Franklin $\mathrm{CL}$. The influence of caging, bedding, and diet on the composition of the microbiota in different regions of the mouse gut. Sci Rep. 2018;8:4065. 
bioRxiv preprint doi: https://doi.org/10.1101/2021.10.26.465755; this version posted October 26, 2021. The copyright holder for this preprint (which was not certified by peer review) is the author/funder. All rights reserved. No reuse allowed without permission.

Maternal gut holobiont and malnutrition in pregnancy

[79] Martinez-Guryn K, Hubert N, Frazier K, Urlass S, Musch MW, Ojeda $P$, et al. Small Intestine Microbiota Regulate Host Digestive and Absorptive Adaptive Responses to Dietary Lipids. Cell Host Microbe. 2018;23:458-69 e5. 
bioRxiv preprint doi: https://doi.org/10.1101/2021.10.26.465755; this version posted October 26, 2021. The copyright holder for this preprint (which was not certified by peer review) is the author/funder. All rights reserved. No reuse allowed without permission.

Maternal gut holobiont and malnutrition in pregnancy

Table A.1. Primer sequences for qPCR

\begin{tabular}{|l|l|}
\hline Name & \multicolumn{1}{|c|}{ Sequence $\left(\mathbf{5}^{\prime} \rightarrow \mathbf{3}\right.$ ') or Reference } \\
\hline \multirow{2}{*}{$A c t b$} & FWD: TCG TGC GTG ACA TCA AAG AGA \\
& REV: GAA CCG CTC GTT GCC AAT A \\
\hline \multirow{2}{*}{$T b p$} & FWD: CGG ACA ACT GCG TTG ATT TTC \\
& REV: AGC CCA ACT TCT GCA CAA CTC \\
\hline \multirow{2}{*}{$Y w h a z$} & $\begin{array}{l}\text { FWD: GCAACGATGTACTGTCTCTTTTGG } \\
\text { REV: GTCCACAATTCCTTTCTTGTCATC }\end{array}$ \\
\hline \multirow{2}{*}{$P p i a$} & FWD: CACCGTGTTCTTCGACATCA \\
& REV: CCAGTGCTCAGAGCTCGAAAG \\
\hline$A b c b 1 a$ & Mm00440761_m1 (Applied Biosystems) \\
\hline$A b c b 1 b$ & Mm00440736 m1 (Applied Biosystems) \\
\hline$A b c g 2$ & Mm00496364_m1 (Applied Biosystems) \\
\hline
\end{tabular}


Table A.2. Multidrug resistance gene mRNA expression in female and male guts at GD18.5.

\begin{tabular}{|c|c|c|c|c|c|c|c|c|}
\hline & \multicolumn{4}{|c|}{ Females } & \multicolumn{4}{|c|}{ Males } \\
\hline & CON & UN & HF & p-value & $\mathrm{CON}$ & UN & HF & p-value \\
\hline \multicolumn{9}{|c|}{ MDR transporters } \\
\hline Abcbla $\mathrm{mRNA}$ & $0.36 \pm 0.20$ & $0.35 \pm 0.16$ & $0.31 \pm 0.12$ & NS & $0.52 \pm 0.22$ & $0.54 \pm 0.18$ & $0.36 \pm 0.11$ & NS \\
\hline$A b c b 1 b$ mRNA & $0.37 \pm 0.14$ & $0.35 \pm 0.20$ & $0.31 \pm 0.10$ & $\mathrm{NS}$ & $0.43 \pm 0.11$ & $0.40 \pm 0.07$ & $0.33 \pm 0.11$ & $\mathrm{NS}$ \\
\hline Abcg2 mRNA & $0.51 \pm 0.23$ & $0.36 \pm 0.10$ & $0.48 \pm 0.12$ & NS & $0.55 \pm 0.14$ & $0.51 \pm 0.12$ & $0.60 \pm 0.19$ & NS \\
\hline
\end{tabular}

Data are mean \pm SD. NS $=$ not significant. 
bioRxiv preprint doi: https://doi.org/10.1101/2021.10.26.465755; this version posted October $26,2021$. The copyright holder for this preprint (which was not certified by peer review) is the author/funder. All rights reserved. No reuse allowed without permission.

Maternal gut holobiont and malnutrition in pregnancy

Table A.3. Correlations between microbial family relative abundance levels and ABC transporter mRNA expression.

\begin{tabular}{|c|c|c|c|c|}
\hline Family & Transporter & $\begin{array}{c}\text { Correlation } \\
\text { coefficient }\end{array}$ & p value & $\begin{array}{c}\text { Corrected } \\
\text { q value }\end{array}$ \\
\hline \multirow[t]{2}{*}{ Pseudanabaenaceae } & Abcbla & 0.80 & 0.001 & 0.022 \\
\hline & Abcg2 & -0.85 & 0.002 & 0.022 \\
\hline \multirow[t]{2}{*}{ Clostridiales Family XI Incertae Sedis } & Abcbla & 0.79 & 0.03 & 0.095 \\
\hline & Abcg2 & -0.90 & 0.002 & 0.022 \\
\hline \multirow[t]{2}{*}{ Oceanospirillaceae } & Abcbla & 0.64 & 0.005 & 0.031 \\
\hline & Abcg2 & -0.80 & 0.002 & 0.022 \\
\hline \multirow[t]{2}{*}{ Acholeplasmataceae } & Abcbla & 0.69 & 0.003 & 0.023 \\
\hline & Abcg2 & -0.87 & 0.0008 & 0.022 \\
\hline \multirow[t]{2}{*}{ Burkholderiaceae } & Abcbla & 0.59 & 0.03 & 0.096 \\
\hline & Abcg2 & -0.59 & 0.006 & $\mathbf{0 . 0 3 7}$ \\
\hline \multirow[t]{2}{*}{ Xanthomonadaceae } & Abcbla & 0.70 & 0.007 & 0.037 \\
\hline & Abcg2 & -0.71 & 0.07 & 0.14 \\
\hline \multirow[t]{2}{*}{ Anaeroplasmataceae } & Abcbla & 0.74 & 0.003 & 0.023 \\
\hline & Abcg2 & -0.75 & 0.008 & 0.046 \\
\hline \multirow[t]{2}{*}{ Methanomicrobiaceae } & Abcbla & 0.73 & 0.005 & 0.034 \\
\hline & Abcg2 & -0.63 & 0.07 & 0.15 \\
\hline \multirow[t]{2}{*}{ Rhodospirillaceae } & Abcbla & 0.79 & 0.002 & 0.022 \\
\hline & Abcg2 & -0.69 & 0.06 & 0.14 \\
\hline \multirow[t]{2}{*}{ Turicibacteraceae } & Abcbla & -0.38 & 0.005 & 0.031 \\
\hline & Abcg2 & 0.36 & 0.26 & 0.37 \\
\hline \multirow[t]{2}{*}{ Bacillaceae } & Abcbla & -0.61 & $<0.0001$ & 0.0003 \\
\hline & Abcg2 & 0.75 & 0.002 & 0.022 \\
\hline \multirow[t]{2}{*}{ Clostridiales Family XIII Incertae Sedis } & Abcbla & -0.67 & 0.002 & 0.022 \\
\hline & Abcg2 & 0.79 & 0.002 & 0.022 \\
\hline \multirow[t]{2}{*}{ Chromatiaceae } & Abcbla & -0.82 & $<0.0001$ & 0.0003 \\
\hline & Abcg2 & 0.77 & 0.004 & 0.031 \\
\hline \multirow[t]{2}{*}{ Spartobacteriaceae } & Abcbla & -0.79 & 0.002 & 0.022 \\
\hline & Abcg2 & 0.78 & 0.01 & 0.051 \\
\hline \multirow[t]{2}{*}{ Clostridiaceae } & Abcbla & -0.78 & 0.0003 & 0.01 \\
\hline & Abcg2 & 0.65 & 0.05 & 0.13 \\
\hline \multirow[t]{2}{*}{ Legionellaceae } & Abcbla & -0.83 & 0.002 & 0.022 \\
\hline & Abcg2 & 0.69 & 0.11 & 0.20 \\
\hline
\end{tabular}

Refer to heatmap Figure 7A. 
bioRxiv preprint doi: https://doi.org/10.1101/2021.10.26.465755; this version posted October $26,2021$. The copyright holder for this preprint (which was not certified by peer review) is the author/funder. All rights reserved. No reuse allowed without permission.

Maternal gut holobiont and malnutrition in pregnancy

Table A.4. Correlations between microbial genus relative abundance levels and ABC transporter mRNA expression.

\begin{tabular}{|l|c|c|c|c|}
\hline \multirow{2}{*}{ Genus } & Transporter & $\begin{array}{c}\text { Correlation } \\
\text { coefficient }\end{array}$ & p value & $\begin{array}{c}\text { Corrected } \\
\text { q value }\end{array}$ \\
\hline \multirow{2}{*}{ Acinetobacter } & $A b c b 1 a$ & -0.68 & 0.003 & $\mathbf{0 . 0 2 4}$ \\
\cline { 2 - 5 } & $A b c g 2$ & 0.51 & 0.09 & 0.21 \\
\hline \multirow{2}{*}{ Eacillus } & $A b c b 1 a$ & -0.61 & $5.3 \times 10^{-6}$ & $\mathbf{0 . 0 0 0 5}$ \\
\cline { 2 - 5 } & $A b c g 2$ & 0.75 & 0.002 & $\mathbf{0 . 0 2 3}$ \\
\hline \multirow{3}{*}{ Xiphinematobacter } & $A b c b 1 a$ & -0.67 & 0.002 & $\mathbf{0 . 0 2 3}$ \\
\cline { 2 - 5 } & $A b c g 2$ & 0.79 & 0.002 & $\mathbf{0 . 0 2 3}$ \\
\hline Clostridium & $A b c b 1 a$ & -0.79 & 0.002 & $\mathbf{0 . 0 2 3}$ \\
\cline { 2 - 5 } & $A b c g 2$ & 0.78 & 0.01 & 0.059 \\
\hline Legionella & $A b c b 1 a$ & -0.78 & 0.0003 & $\mathbf{0 . 0 0 9}$ \\
\cline { 2 - 5 } & $A b c g 2$ & 0.65 & 0.05 & 0.15 \\
\hline \multirow{2}{*}{ Methanogenium } & $A b c b 1 a$ & -0.83 & 0.002 & $\mathbf{0 . 0 2 3}$ \\
\cline { 2 - 5 } & $A b c g 2$ & 0.69 & 0.11 & 0.23 \\
\hline Acholeplasma & $A b c b 1 a$ & 0.73 & 0.005 & $\mathbf{0 . 0 4}$ \\
\cline { 2 - 5 } & $A b c g 2$ & -0.63 & 0.07 & 0.19 \\
\hline Pseudanabaena & $A b c b 1 a$ & 0.66 & 0.002 & $\mathbf{0 . 0 2 3}$ \\
\cline { 2 - 5 } & $A b c g 2$ & -0.92 & $5.1 \times 10^{-5}$ & $\mathbf{0 . 0 0 3}$ \\
\hline Anaeroplasma & $A b c b 1 a$ & 0.80 & 0.001 & $\mathbf{0 . 0 2 3}$ \\
\cline { 2 - 5 } & $A b c g 2$ & -0.85 & 0.002 & $\mathbf{0 . 0 2 3}$ \\
\cline { 2 - 5 } & $A b c b 1 a$ & 0.74 & 0.003 & $\mathbf{0 . 0 2 4}$ \\
\cline { 2 - 5 } & $A b c g 2$ & -0.75 & 0.008 & 0.057 \\
\hline
\end{tabular}

Refer to heatmap Figure 7B. 
bioRxiv preprint doi: https://doi.org/10.1101/2021.10.26.465755; this version posted October 26, 2021. The copyright holder for this preprint (which was not certified by peer review) is the author/funder. All rights reserved. No reuse allowed without permission.

Maternal gut holobiont and malnutrition in pregnancy

\section{Supplementary Figure A.1}

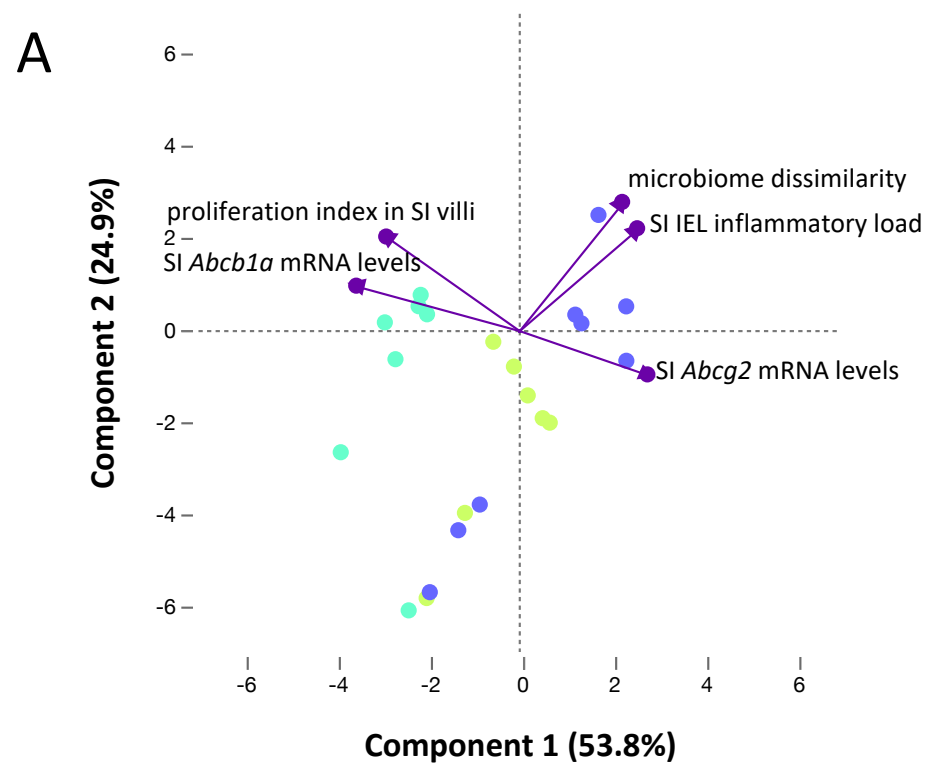

B

\begin{tabular}{|l|c|c|c|c|c|}
\hline Feature & PC1 & PC2 & PC3 & PC4 & PC5 \\
\hline Abcb1a mRNA expression in SI & $-\mathbf{0 . 9 1 3 1 2}$ & 0.24916 & 0.07676 & 0.20533 & 0.23682 \\
\hline Abcg2 mRNA expression in SI & $\mathbf{0 . 7 2 3 0 2}$ & -0.24905 & 0.60871 & 0.20651 & 0.04514 \\
\hline Ki67 proliferation index in SI villi & $\mathbf{- 0 . 7 4 4 6 7}$ & $\mathbf{0 . 5 2 5 0 4}$ & 0.36032 & 0.03590 & -0.19667 \\
\hline Microbial abundance dissimilarity (mean wUniFrac) & $\mathbf{0 . 5 8 1 2 3}$ & $\mathbf{0 . 7 1 9 4 3}$ & 0.13898 & -0.33735 & 0.10707 \\
\hline SI IEL inflammation summary score & $\mathbf{0 . 6 6 5 5 6}$ & $\mathbf{0 . 5 7 1 5 5}$ & -0.27417 & 0.39214 & -0.03767 \\
\hline
\end{tabular}

